\title{
Insuring Children Against Parental Incarceration Risk
}

\author{
Angela Cai $\dagger$
}

ABSTRACT: In the United States, where government policies have resulted in extremely high incarceration rates, parental incarceration is a prevalent, distinct, and severe form of childhood disadvantage. Children who lose their parents to incarceration suffer unique harms, which are not addressed by current social insurance programs. In particular, an inmate's child suffers direct financial harm from losing financial and in-kind support, from diversion of household resources to the incarcerated inmate parent, and from deficits in future contributions due to the parent's ex-felon status. Children of incarcerated parents tend to already be poor, and these additional deprivations create severely negative consequences for their welfare. This Article proposes that the state should provide children with incarceration insurance: an upfront subsidy to the child whose parent goes to prison, to be repaid to the state by the incarcerated parent on a deferred basis in lieu of child support. The state should supply this social insurance program because of its interest and obligation in promoting child welfare and enforcing parental responsibility. The United States in particular has a strong obligation to the children who bear hidden costs of the government's choice to pursue an aggressive criminal punishment regime that disproportionately harms poor and minority children. This proposal is an innovative departure from the status quo, which does little to support children while allowing child support arrears to accrue against inmate parents. The proposal allows for a menu of implementation options that states can choose from to fit their own circumstances and needs. A baseline version of the proposal engages with the question of how to assign family responsibility, legal and philosophical inquiries about desert, and how to mitigate the impact of localized disadvantage on broader society. The resulting policy regime thus must support the basic motivations behind the proposal: to plug a resource gap and thus promote child welfare, especially for disadvantaged children, to maintain the bonds of parental obligation while incarceration forces physical removal, and to propel the state to neutralize the effects of its own role in

† J.D. 2014, Yale Law School. Many thanks to Anne Alstott, Vicki Schultz, Hillard Pouncy, Zachary Herz, and the participants of the 2012 Family, State, and Market workshop seminar at Yale Law School for their thoughtful comments and suggestions. Thanks also to my superb editor at the Yale Journal of Law and Feminism, Claire Simonich. Any errors are mine alone. 
driving up parental incarceration for disadvantaged children. Doing so will allow both the parent and the state to internalize some collateral costs of mass incarceration currently borne by innocent third parties.

I. INTRODUCTION

II. WHY CHILDREN NEED INCARCERATION INSURANCE: THE IMPACT OF PARENTAL INCARCERATION ON CHILD WELL-BEING. .98

A. Parental Incarceration as a New American Epidemic.................. 99

B. Parental Incarceration as a Discrete Driver of Childhood Disadvantage

C. The Severity of Parental Incarceration Disadvantage................. 120

III. INCARCERATION INSURANCE ..................................................... 123

A. The Moral Status of Children ................................................. 124

B. Rectifying Mass Incarceration's Harms to Children................... 127

C. Social Impact of Mass Parental Incarceration............................ 134

IV. Defining Parental Obligation ................................................. 138

A. Why Parents Must Pay ....................................................... 138

B. Impact on Inmates.............................................................. 139

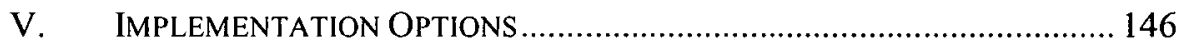

A. Incarceration Insurance as Social Insurance ............................... 146

B. The Policy Landscape........................................................ 147

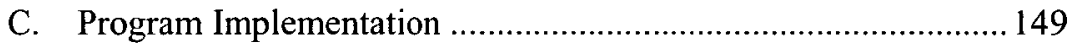

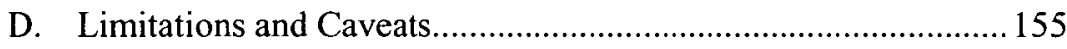

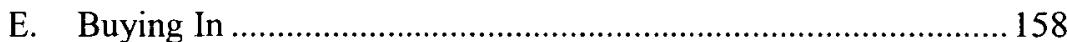

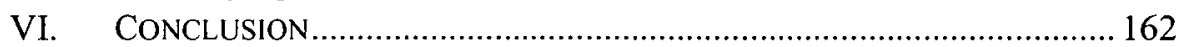

\section{INTRODUCTION}

People exit their parental obligations for many reasons, legitimate and illegitimate. ' In an ideal world, parents stay to provide continuity of support for their children at the expense of some other pursuit: a new life, a new spouse, a new family. In the real world, of course, some parents choose to leave for precisely those ordinary reasons. But there is another form of parental exit. This exit is not as obviously a matter of choice, and it is becoming more and more prevalent.

This exit is the American prison system. ${ }^{2}$ It is the door through which many American children see their parents leave. In 2008, 2.6 million $^{3}$ children

1. See ANNE ALSTOTT, No EXIT 40 (2004)

2. Throughout this paper I will refer to the word "prison" to include both inmates in prisons but also in jails. There are important distinctions between these two penal institutions, but for the purpose of evaluating risks to children of incarcerated parents, those distinctions are not central. 
in America-3.5 percent of the total minor population ${ }^{4}$-had incarcerated parents. Around seventy percent of these children were children of color. ${ }^{5}$ Accordingly, the risk of parental incarceration is staggeringly high for AfricanAmerican children. A black child born in 1990 has a one in four chance of having her father incarcerated by the time she turns fourteen. ${ }^{6}$ If her father is also a high school dropout, the risk of parental incarceration is over fifty percent. ${ }^{7}$

Incarceration imposes myriad collateral consequences upon inmates, their families and associates, and society at large. In this Article, I focus on the concrete, financial aspect of parental incarceration's damage to children. ${ }^{8}$ When the parent of a child goes to prison, the child may lose parental income for basic material needs. The family's remaining income may be redirected to support the incarcerated parent. The child loses his parent's physical care, guidance through education and socialization, and representation of interests in the broader community. ${ }^{9}$ When parents go to prison, the real consequences for their children, many of whom are already disadvantaged, are severe. Hunger and other forms of marked material deprivation are not uncommon. ${ }^{10}$ These and other impacts of incarceration lead children and other family members to feel as if they are "doing time" with the inmate."

Parental incarceration is a prevalent, distinct, and severe form of childhood disadvantage in the United States. Though the government provides some protections against other forms of parental exits in setting up social insurance and social welfare programs, none target the specific disadvantages conferred

3. BeCky Pettit, InVisible Men: Mass InCARCERATION AND tHe Myth of BLACK Progress 83 (2012) (extrapolating from other studies the number of children under age 18 with a parent in prison or jail in 2008). Another estimate of children with parents in either jail or prison is 2.4 million. NELL BERNSTEIN, ALL ALONE IN THE WORLD 2 (2005) (citing correspondence with Christopher Mumola, a statistician at the Bureau of Justice Statistics).

4. There were 74.1 million American children ages 0 to 17 in 2008. Child Population (Table), Federal INTERAGENCY FORUM ON ChILd AND FAMILY STATISTiCs, http://www.childstats.gov/ americaschildren/tables/pop l .asp?popup=true (last visited Feb. 28, 2013).

5. Sarah Schirmer et al., Incarcerated Parents and Their Children: Trends 1991-2007, THE SENTENCING PROJECT 7 (2009), http://www.sentencingproject.org/doc/publications/publications/ inc_incarceratedparents.pdf.

6. Christopher Wildeman, Parental Imprisonment, the Prison Boom, and the Concentration of Childhood Disadvantage, 46 DEMOGRAPHY 265, 270-71 (2009).

7. Id. at 266 . At any given point in time, $7 \%$ of black children and $0.8 \%$ of white children have a parent in prison. $I d$.

8. See TODD A. Clear, IMPrisoning COMMUnities 130 (2007) (noting the importance that families of incarcerated inmates place on financial losses). For an overview of other types of collateral consequences of prisons, see Michael Tonry \& Joan Petersilia, American Prisons, in PRISONs (Michael Tonry \& Joan Petersilia eds., 1999).

9. As Donald Braman points out, these effects are "particularly devastating to poor families because they generally have the highest marginal costs . . . any additional expenses or burdens cut closer to the bone." DONALD BRAMan, DoING Time on THE OUTSIDE: INCARCERATION AND FAMILY LIFE IN URBAN AMERICA 158 (2004).

10. See CleAR, supra note 8 , at 131.

11. See BRAMAN, supra note 9. 
by parental incarceration itself. Children of incarcerated parents are thus left with little recourse. That so many American children lose parents to the prison system is a "national tragedy" 12 because when a parent goes to prison, children lose a critical source of support that is not made up in any other way. Children themselves are blameless in this tragedy. No matter how we conceptualize the parents' culpability, children do not direct their parents' conduct or, indeed, choose their parents. Yet all children need physical goods, emotional support, education, and adequate representation of their interests.

In our society, we expect parents to act as the primary provider of most of these resources. But when reality falls short of that expectation, an alternate plan should kick in. In the face of that reality, the state should strike a balance between parental incapacitation and parental responsibility in its effort to provide for children's needs. I contend that although some parents make a deliberate choice in breaking the law, the state also bears considerable responsibility for the consequences of incarcerating these parents, which are often borne by their children. Children should be understood as persons of special concern to the state because it has a special obligation to them, because investing in child welfare results in positive social returns, and because the state in particular has an obligation to children of incarcerated parents, who bear hidden costs of the government's particularly aggressive criminal punishment regime. In accord with ideals of equal opportunity and fundamental fairness, then, children whose parents are incarcerated need and deserve incarceration insurance.

Thus, I propose a form of new social insurance, which would enlist the state in providing children with a bulwark against the financial risk of parental imprisonment. ${ }^{13}$ This "incarceration insurance" requires the government to pay a subsidy to children, perhaps subject to a maximum dollar and time restriction. The incarcerated parents accrue obligations while in prison, and pay back to the government through a graduated and deferred payroll tax once they are released. The likely gap between government payments to children and parental repayments would be funded by tax revenue.

This novel proposal for incarceration insurance would assist almost all children of incarcerated parents. ${ }^{14}$ Ninety-two percent of incarcerated parents

12. Julie Poehlmann \& J. Mark Eddy, A Research and Intervention Agenda for Children of Incarcerated Parents, in CHILDREN OF INCARCERATED PARENTS 319, 338 (J. Mark Eddy \& Julie Poehlmann eds., 2010) [hereinafter CHILDREN OF INCARCERATED PARENTS 2010].

13. This proposal does not at first glance look like traditional insurance, but from the perspective of the child at risk, it performs the same function. See infra Part V.A for a discussion of how the proposal can be conceptualized as social insurance.

14. One exception would be for children who are already in foster care. Only $2 \%$ of incarcerated fathers and eleven percent of incarcerated mothers reported having children in foster care or other agency care. A large portion of these children were already in foster care when their parents were incarcerated. Laura M. Maruschak, Lauren E. Glaze \& Christopher J. Mumola, Incarcerated Parents and Their Children, Findings from the Bureau of Justice Statistics, in CHILDREN OF INCARCERATED PARENTS 2010, supra note 12 , at 33, 42. However, this phenomenon may be growing because of an 
are fathers, and 8 percent are mothers, ${ }^{15}$ but mothers were much more likely to have been the only parent living with their children before incarceration than were the fathers (42 percent versus 17 percent). ${ }^{16}$ For inmates who were not single parents (either noncustodial parents or coparents), their children continue to live with the other parent but without resources from the inmate parent. On the other hand, children who lose their sole parent to prison suffer a massive disruption as they must transition to living with more distant family or with a foster family. Thus, though the state sometimes provides some social insurance, such as foster care, for children who have two parents unable to care for them, it fails to provide for the loss of one parent to prison. In total, 84 percent of incarcerated parents reported that their child's current caregiver is the other parent and 15 percent reported that their child currently lives with grandparents or other relatives. $^{17}$

Though skeptics may wonder how the removal of a "deadbeat" parent actually harms children, social science research shows that even parents who did not live with their children and even those who owed back child support nonetheless contributed to their children's lives through other funds, gifts, and care. ${ }^{18}$ In addition, the very act of separation is a form of trauma from the perspective of the child. ${ }^{19}$ Thus, for most parents who go to prison, their incarceration is damaging for their children in real and tangible ways.

In the United States, mass incarceration can be aptly characterized as "a hidden tax, one that is visited disproportionately on poor and minority

increasing tendency for the state to begin parental termination proceedings for incarcerated parents. See Deseriee A. Kennedy, Children, Parents and the State: The Construction of a New Family Ideology, 26 BERKELEY J. GENDER L. \& JUST. 78 (2011); Caitlin Mitchell, Note, Family Integrity and Incarcerated Parents: Bridging the Divide, 24 YALE J. L \& FEMINISM 175 (2011).

15. Lauren E. Glaze \& Laura M. Maruschak, Special Report: Parents in Prison and Their Minor Children, BUREAU OF JUSTICE STATISTICS, U.S. DEP'T OF JUSTICE, 2 (2008), http://www.bjs.gov/content/pub/pdf/pptmc.pdf Throughout this paper, I will sometimes refer to incarcerated parents as "fathers" or "he," but only as shorthand. Though I am by no means supporting a gender-normative view of incarcerated parents, the shorthand is sometimes necessary because much of the empirical literature on mass incarceration focuses on men, who make up the vast majority of inmates. Therefore, the conclusions drawn from the empirical data sometimes must be limited to the population studied.

16. Id. at $\mathbf{4}$ (providing data for state prisons). For existing studies that focus on female inmates who were the primary and sometimes sole caregivers of their minor children, see, for example, the research of Barbara Bloom, Christina Jose Kampfner, and Denise Johnston in CHILDREN OF INCARCERATED PARENTS (Katherine Gabel \& Denise Johnston eds., 1995) (hereinafter CHILDREN OF INCARCERATED PARENTS 1995). Fewer studies target the experiences of incarcerated fathers. But see ANNE NURSE, FatherhoOd arRested: Parenting from Within the JuVEnile Justice System 6 (2002); BRAMAN, supra note 9. There is also overlap between children with mothers and fathers in prison. About two-thirds of children whose mothers have been arrested also had their fathers arrested. Teenagers whose fathers have been arrested are 11 times more likely to have mothers who have been arrested versus teens who have never-arrested fathers. See Susan D. Phillips, The Past as Prologue: Parental Incarceration, Service Planning, and Intervention Development in Context, in CHILDREN OF INCARCERATED PARENTS 2010, supra note 12, at 13, 16.

17. Glaze \& Maruschak, supra note 15 , at 5.

18. See infra Part II.B. I and Part II.B.5.

19. See BERNSTEIN, supra note 3, at 3, 31 . 
families." ${ }^{20}$ The incarceration insurance program I propose operates on a universal framework but will likely have targeted effects on minority populations; it mirrors the mass incarceration system, which is also universal in definition but has heavily-skewed impact on minorities. As the prison boom over the past three decades has almost been exclusively concentrated on undereducated, disadvantaged, African-American men, ${ }^{21}$ the families who care for children of incarcerated parents are likely to be disadvantaged as well. Thus, the marginal support provided to children through incarceration insurance is especially necessary.

Current legal and social systems fail children of incarcerated parents in two ways. First, existing work (both scholarship and policy) on social insurance largely ignores parental incarceration as a major driver of childhood disadvantage. Skeptics may immediately wonder why a program for incarceration insurance is needed when there are other assistance funds-such as foster care, welfare assistance, tax credits, housing subsidies, food stamps, and Medicaid-that benefit poor children. ${ }^{22}$ The reality is that though disadvantaged children receive some assistance from the state, the existing programs are neither sufficient as a general matter, nor substantially helpful for the specific harm visited by parental incarceration, which exacerbate the harm to children who are already poor. Programs that aim to insure children against catastrophic events are woefully inadequate because they miss wide swaths of the vulnerable. For example, Social Security survivor benefits protect the dependents of working parents from the risk of income insecurity resulting from death or disability, but it cannot help the vast majority of poor children. ${ }^{23}$ Foster care only kicks in when both parents are unable to care for their children, leaving out the majority of children of incarcerated parents. While state and federal governments aggressively pursue child support order establishment and payment, ${ }^{24}$ when the parent goes to prison, the child receives

20. BRAMAN, supra note 9 , at 156 .

21. See Bruce Western, Reentry: Reversing Mass Imprisonment, Bos. Rev (July 1, 2014), ("Among young black men who have never been to college, one in five are incarcerated, and one in three will go to prison at some time in their lives. The intimate link between school failure and incarceration is clear at the bottom of the education ladder where 60 percent of black, male high school dropouts will go to prison before age thirty-five.").

22. For an overview of each of programs that ward off some of the risks of being born into poverty, see Theodore R. Marmor, Jerry L. Mashaw \& John PakUtKa, Social insurance: America's NEgLECTED HERITAGE AND CONTESTED FUTURE 71-82 (2014) (describing programs such as TANF, Earned Income Tax child credits, dependent tax exemptions, food stamps (SNAP), nutrition supplement funding (WIC) and child health care (SCHIP)).

23. In particular, these include those born into "single, divorced, or never-married parent households that account for a substantial percentage of childhood poverty." MICHAEL J. GRAETZ \& JERRY L. MASHAW, TRUE SECURITY: RETHINKING AMERICAN SOCIAL INSURANCE 6 (1999).

24. The federal government has made a significant effort to increase child support enforcement over the past 40 years. The federal government's commitment to child support enforcement includes both funding state collection costs and setting collection thresholds for states to meet. For example, the Child Support Enforcement Amendments of 1984, Pub. L. No. 98-378, 98 Stat. 1305, amending 42 U.S.C. $\$ \S 657-662$, made states establish guideline numbers and withhold child support from wages of 
no support. Other innovative policy proposals to improve the state of poor children have not come to fruition, and none address parental incarceration specifically and adequately. In the absence of a more ambitious and effective social insurance strategy, the state should strive for incarceration insurance.

Second, the criminal justice system does not adequately address children's interests, and the child welfare system stands woefully inadequately in the face of mass incarceration. Sociological and legal studies discuss the reign of the American penal state by examining its implications for the labor market, ${ }^{25}$ for the livelihoods of those who get incarcerated, ${ }^{26}$ for dynamics in hyper-policed communities, ${ }^{27}$ for racial justice, ${ }^{28}$ and for societal safety. ${ }^{29}$ Studies that do turn to incarcerated parents tend to focus on the emotional and behavioral effects on inmates and their families and typically conclude with proposals to improve access to visitation, prison parenting classes, and the like. ${ }^{30}$ These problems and the proposed reforms are important. However, it is difficult to parse out just how to alleviate socio-emotional damage on a large population of vulnerable children who are not similarly situated. The proposals on prison policies are probably helpful, but their mandates are too narrow and too tangential to the direct needs of children; they also ignore the major problem of resource deprivation. The loss of financial contribution is a direct mechanism by which parental incarceration affects children, and incarceration insurance addresses it head-on.

In assessing these failures, I argue that the state cannot ignore its responsibility to promote child well-being in its efforts to punish parents. It is a fallacy to believe that "we can make things harder for parents without making them worse for children." 31 Rather, the state must fulfill its obligation to children by providing a least-detrimental alternative. ${ }^{32}$ Incarceration insurance does just that, by calling on both parents and the state to act on their duties owed to children. It aims to do so thoughtfully, by recognizing the limitations

those who didn't pay. For a more detailed but concise account of the history of child support policy in the United States prior to 1996 welfare reform, see IRWIN GARFINKEL, ASSURING CHILD SUPPORT 18-31 (1992). Analysts also observe that at least a large part of the federal child support enforcement agenda is cost recovery. See id. at 144.

25. See, e.g., Bruce Western \& Katherine Beckett, How Unregulated Is the US Labor Market? The Penal System as a Labor Market Institution. 104 AM. J. SOC. 1030 (1999).

26. See, e.g., Western, supra note 21.

27. See, e.g., Alice GofFman, On the Run: Fugitive LifE IN AN AMERICAN City (2014).

28. See, e.g., MiCHElle AleXANDER, THE NEW Jim Crow (2010).

29. See, e.g., CLEAR, supra note 8.

30. See, e.g., BERNSTEIN, supra note 3, at 260-68; Denise Johnston, Intervention, in CHILDREN OF INCARCERATED PARENTS 1995, supra note 16, at 199.

31. BERNSTEIN, supra note 3, at 144.

32. JOSEPH GOLDSTEIN, ANNA FREUd \& ALBERT J. SOLNIT, BEFORE THE BEST INTERESTS OF THE CHILD 11 (1979) [hereinafter GoldSTEIN, FREUd \& SOLNIT, BEFORE BEST INTERESTS]; BERNSTEIN, supra note 3, at 259 ("When the arrest and incarceration of a parent are genuinely necessary, it remains our responsibility to seek a 'least detrimental alternative' to take steps to protect and support children at every step of the process, from arrest to reentry."). 
of already-disadvantaged inmates, and by balancing those limitations against the needs of children. As a whole, the proposal should be on the agenda of legal scholars and academics because it stems from the legal structure of mass incarceration, and because crafting a solution requires attention both to the complex backdrop of public benefits law and theories of legal and political obligation.

The next section, Part II, marshals both quantitative and qualitative empirical studies to demonstrate that parental incarceration is a pervasive, discrete, and significant form of childhood disadvantage. It tracks the ways in which parental incarceration creates economic and noneconomic harms, including loss of current economic support, increased costs to families, lowered future income, and socio-emotional damage to children. Part III argues that this disadvantage merits societal intervention for three reasons. First, the state has a special obligation to children, who are both morally blameless and deserving of care. Second, the American government should rectify hidden harms to children generally, who bear the unrealized costs of the government's incarceration policies, and to minority children specifically, because the state must correct for the dramatically unequal starting points for different children as a result of discriminatory criminal law administration. Third, the state has an obligation to address the negative societal spillover effects of parental incarceration. Part IV explores the division of responsibility between the parents and the state in providing for children's needs, arguing that while the state cannot sit idle, incarcerated parents also have an obligation to pay back. It also examines what this duty would mean for both inmate parents and nonincarcerated parents. Part V discusses implementation options, first by situating the proposal as an social insurance program against a backdrop of other innovative proposals, and then by analyzing a matrix of implementation considerations, exploring questions such as how to initiate claims, how much to pay the children, how much the parents should pay back, timelines, prison work considerations, and enforcement mechanisms. It addresses some counterarguments, caveats, and the question of political and cultural feasibility. Finally, the paper concludes with a few observations about how we should respond to the parental incarceration epidemic as a uniquely American phenomenon.

\section{WHY CHILDREN NEED INCARCERATION INSURANCE: THE IMPACT OF PARENTAL INCARCERATION ON CHILD WELL-BEING}

In America, parental incarceration has become a prevalent, distinct, and severe form of childhood disadvantage. This Part provides empirical support for each of these three claims. It is important to carefully assess the impact of parental incarceration on children because the underlying motivation for the 
proposal for incarceration insurance rests on the idea that the program would address a significant harm. Since the insurance system I propose aims to benefit children, the analysis below also focuses on them.

\section{A. Parental Incarceration as a New American Epidemic}

Many American parents are behind bars because the United States has an aggressive incarceration regime. America's mass imprisonment regime is staggering. At 756 individuals per 100,000 in the population behind bars, the United States has the highest incarceration rate in the world, surpassing China, Iraq, Cuba, and Russia. ${ }^{33}$ The American incarceration rate is several times greater than those of Western Europe and other developed countries. ${ }^{34}$ As of the end of 2010,1.5 million individuals were held in prisons in the United States. ${ }^{35}$ This high level of imprisonment is also accompanied by a rate of prison population growth. The number of people incarcerated increased by at least 35,000 per year from 1980 to 2000 . In the "high periods" such as $1989-90$, the increase was $127,500 .^{36}$ The rate has risen by 1.6 percent from 2000 to $2009 .{ }^{37}$ For American men, the risk of imprisonment rose from 1.9 percent to 6.6 percent in the period between 1974 and $1997 .{ }^{38}$

Even more striking than the sheer volume of incarceration is its distribution. The incarceration boom in the United States since the 1970s has hardly been an equal-opportunity amasser of prisoners. ${ }^{39}$ Nearly one-third of black men will have been incarcerated at some point in their lives, compared to 1 in 17 white men. ${ }^{40}$ Black men born in the period 1965 to 1969 , just before the War on Drugs took effect, are 7 times more likely to have been incarcerated than white men of the same cohort. ${ }^{41}$ When compounded with prevalent low educational attainment, these figures become starker. For black males born between 1965 and 1969 who dropped out of high school (which is not an independent variable by any means), nearly 60 percent had been to prison by

33. Roy Walmsley, World Prison Population List, Eighth Edition, KING'S COLLEGE LONDON: INTERNATIONAL CENTRE FOR PRISON STUDIES, available at http://www.prisonstudies.org/info/

downloads/wppl-8th_41.pdf. The figures for China are 119 per 100,000 (accounting for administrative detention, the figure is 183), Iraq: 93, Cuba: 531, and the Russian Federation: 629.

34. Id. France had 96 in 100,000 incarcerated, Germany had 89, Canada had 116, Australia had 129, and England and Wales had 153. Id.

35. See Lauren Glaze, Correctional Population in the United States 2010, BuREAU OF JUSTICE STATISTICS, U.S. DEP'T OF JUSTICE, 3 (2011), http://www.bjs.gov/content/pub/pdf/cpus 10.pdf.

36. See MEgan COMfort, DOING Time TOGETHER: Love and Family IN THE SHAdow of the PRISON 5-6 (2008).

37. See id. at 6.

38. See Thomas P. Bonczar, Prevalence of Imprisonment in the U.S. Population, BuREAU OF JUSTICE STATISTICS, U.S. DEP'T OF JUSTICE 7 (2003), available at http://www.bjs.gov/content/pub/pdf/ piusp01.pdf.

39. See Alexander, supra note 28; Michael TONRY, Punishing RaCe 34-37 (2011).

40. BONCZAR, supra note 38 .

41. Id. 
$1999 .^{42}$ On any given day, a third of black men who did not complete high school are behind bars. ${ }^{43}$ Black women are 3 times more likely to be incarcerated than white women. ${ }^{44}$ As Michelle Alexander observes in arguing that mass imprisonment in the United States entrenches a racial caste system under the guise of colorblindness, "[t]he United States imprisons a larger percentage of its population than South Africa did at the height of apartheid" and "three out of four black young men" are behind bars in Washington, D.C. ${ }^{45}$ The locations that supply prisons with inmates are clustered and map onto the poor, minority neighborhoods in the inner cities. ${ }^{46}$

The incarcerated are not unfettered individuals. A 2010 Bureau of Justice Statistics special report found that 52 percent of state and 63 percent of federal prisoners reported having minor children; the prisoners had an average of two children. ${ }^{47}$ Based on sociologists' estimates, some 3.5 percent of children in the United States-over 2.6 million-had a parent in prison or jail in the year $2008 .^{48}$ The vast majority (about 90 percent) of these children had an incarcerated father as opposed to a mother. ${ }^{49}$

As a result, the likelihood that a child experiences parental incarceration is high. Performing the first robust estimates of the prevalence of parental imprisonment in populations of children, sociologist Christopher Wildeman extrapolated the risk of parental imprisonment for black and white children born between 1978 and $1990 .^{50}$ For black children in 1990, the risk that a parent would go to prison by the time they turned age 14 was more than 25 percent, versus a less than 4 percent risk for white children. ${ }^{51}$ For black children born in 1990 to a high school dropout, the risk of having a parent incarcerated was greater than 50 percent. ${ }^{52}$ On any given day, one in 10

42. See Becky Pettit \& Bruce Western, Mass Imprisonment and the Life Course: Race and Class Inequality in U.S. Incarceration, 69 AM. SOC. REV. 151 (2004).

43. See BRUCE WESTERN, PUNISHMENT AND INEQUALITY IN AMERICA 17 (2006).

44. Incarcerated Women, THE SENTENCING PROJECT, 2 (2012), http://www.sentencingproject.org/ doc/publications/cc_Incarcerated_Women_Factsheet_Sep24sp.pdf.

45. ALEXANDER, supra note 28 , at 12 .

46. Id.

47. Glaze \& Maruschak, supra note 15, at 1. The findings are based on the BJS's 2004 survey on inmates in federal and state facilities.

48. PETTIT, supra note 2.

49. Id.

50. See Wildeman, supra note 6 , at 265 . Other researchers have suggested other estimates. For example, the Center for Children of Incarcerated Parents suggested a formula: (\# of incarcerated women x 0.75 (percent of incarcerated women w/ children) ) $\times 2.4$ (avg number of children per mom) + ( \# of incarcerated men $\times 0.56$ (avg \% of incarcerated men with children) ) $\times 2$ (avg number of children per incarcerated father). Cynthia Seymour, Introduction, in CHILDREN WITH PARENTS IN PRISON: CHILD Welfare Policy, Program, AND Practice Issues 489 n.1 (Cynthia Seymour \& Creasie Finney Hairston, eds., 2001).

51. Wildeman, supra note 6 , at 271.

52. Id. at 277 . 
African-American children has a parent incarcerated, versus one in 100 white children. ${ }^{53}$

The population of children exposed to parental incarceration risk is also staggering in size and growing. The rate of growth for having a parent in prison was 80 percent between 1991 and 2007, matching the growth rate in incarcerated parents (79 percent). ${ }^{54}$ Though the peak in parental incarceration occurred between 1991 and 1997, the next 10 years saw a steady growth pace of 25 percent. ${ }^{55}$ The number of children with a mother in prison was up 131 percent from 1991 to 2007 , versus a 77 percent growth in the number of children with a father in prison. ${ }^{56}$

Because the prison population in the United States is predominantly poor and come from minority populations, and because there is a high level of intraracial and intra-class assortive mating, parental incarceration risk is also skewed along racial and class dimensions. Black children are nine times more likely to have a parent in prison than white children, and Hispanic children are three times more likely. ${ }^{57}$ Though the problem of parental exit through incarceration is theoretically universal-it happens regardless if one's parent is black or white, male or female, rich or poor-the problem's pervasiveness in American society makes it especially worthy of exploration.

For many swaths of the already-disadvantaged children in the U.S., parental incarceration is a rite of passage into greater disadvantage. The pervasiveness problem can be solved if the U.S. dramatically reduced the number of people incarcerated and the length of time prisoners spend behind bars. Yet any politically feasible interventions will likely proceed gradually. Furthermore, sociologists estimate that even if we were to return instantly to 1970 s levels of incarceration (100 individuals per 100,000), the effects of mass incarceration-including deprivations for inmates' children-are likely to linger for another generation. ${ }^{58}$

53. Christopher Wildeman \& Bruce Western, Incarceration in Fragile Families, 20 FuTURE OF CHILDREN 157, $162(2010)$.

54. There were 945,600 children with parents in state and federal prison in 1999. By 2007 it was $1,706,600$. In 1999, there were 452,500 parents in state and federal prison. By 2007 it was 809,800 . Calculations were based on statistics provided by Glaze \& Maruschak, supra note 15, at 13.

55. There was a 44 percent increase in both the number of children with parents in prison and in the number of incarcerated parents between 1991 and 1997. Between 1997, the increase was 25\% for both figures. Calculations were based on statistics provided by Glaze \& Maruschak, supra note 15, at 13.

56. There were 63,900 children with a mother in state or federal prison in 1991, versus 147,400 such children by 2007 . There were 881,500 children with fathers in prison in 1991 , versus $1,559,200$ in 2007. Calculations were based on statistics provided by Glaze \& Maruschak, supra note 15, at 13.

57. Nancy G. La Vigne, Elizabeth Davies \& Diana Brazzell, Broken Bonds: Understanding and Addressing the Needs of Children with Incarcerated Parents, URBAN INSTITUTE JUSTICE POLICY CENTER 2 (2008).

58. Christopher Wildeman, Presentation at the Yale University Edward Zigler Center in Child Development \& Social Policy Lecture Series (Nov. 30, 2012) (notes on file with author). 


\section{B. Parental Incarceration as a Discrete Driver of Childhood Disadvantage}

The exit of a parent due to incarceration hampers child well-being. A common statistic asserts that these children are six times more likely to be incarcerated themselves than their peers, though this claim is not directly attributed to specific sources. ${ }^{59}$ Yet empirical evidence of the harm, some with far-reaching consequences, is not difficult to find. And though the very separation of a child from his parent might be theorized as a per se deprivation, ${ }^{60}$ this proposal builds on a more concrete, empirical foundation and identifies specific harms derived from parental incarceration.

There are least three causal paths for parental incarceration to negatively affect childhood economic security: the loss of financial and quasi-financial contributions while incapacitated in prison, the increased economic strain on other caregivers while a parent is in prison, and the present value of future losses caused by reduced labor wages when these parents get out of prison. Parental incarceration also leads to various forms of noneconomic deprivation, including socio-emotional and physical health damage. This section traces each of these three economic drivers of resource deprivation in detail and provides supporting corroboration from ethnographical and statistical studies; it then turns to noneconomic harms. It concludes by synthesizing these causal mechanisms and addresses counterclaims.

It is virtually impossible to compare the counterfactual results of not having any particular parent going to prison to the reality that his child faces when he does go. ${ }^{61}$ Nevertheless, there is ample empirical evidence that children of incarcerated parents experience particular hardships not suffered by similarly situated children whose parents were never incarcerated. ${ }^{62}$ This section will introduce these evidence, most of which are culled from analysis of

59. J. Mark Eddy \& Julie Poehlmann, Multidisciplinary Perspectives on Research and Intervention with Children of Incarcerated Parents, in CHILDREN OF INCARCERATED PARENTS 2010, supra note 12, at 1 .

60. See Phillips, supra note 16 , at 24 . Phillips frames the harm as procedural, that is, that parental incarceration is a per se harm for children and its alleviation "is a matter of justice and does not hinge on demonstrating a relationship between parental incarceration and adverse child outcomes." $I d$.

61. Controlled experiments are virtually impossible when it comes to criminal incarceration.

62. See Ofira Schwartz-Soicher, Amanda Geller \& Irwin Garfinkel, The Effect of Paternal Incarceration on Material Hardship, 85 SOC. SERV. REV. 447, 469 (2011) (finding that "material hardship is much more intense for families experiencing a paternal incarceration than for those with no such experience," and noting that though the underlying Fragile Families dataset does not guarantee a causal link, the difference in the finding "is unlikely to be explained by unobserved heterogeneity between the two types of families"). See also Amanda Geller et al., Parental Incarceration and Child Well-being: Implications for Urban Families, 90 SoC. SCI. Q. 1186, 1198, 1200 (2009) [hereinafter Geller et al., Parental Incarceration and Child Well-being] (finding heightened economic hardship, residential instability, and behavioral problems for children of incarcerated parents, versus children with never-incarcerated parents in the Fragile Families dataset); Susan D. Phillips et al., Disentangling the Risks: Parent Criminal Justice Involvement and Children's Exposure to Family Risks, 5 CRIM. \& PUB. POL'Y 677 (2006) (noting that parental incarceration has a strong association with heightened family resource strain). 
the longitudinal Fragile Families and Child Well Being study in the 1990s, which reached thousands of urban families of unmarried parents, and interviewed mothers and fathers at time of birth of their children and when the children were one, three, and five years old. ${ }^{63}$

\section{Loss of Direct Economic Support through Incarceration}

The economic instability precipitated by parental incarceration begins with the loss of everyday economic support from the parent. ${ }^{64}$ Empirical studies show that "[t]he most common answer residents [of a low-income neighborhood] gave regarding the impact of incarceration and their lives had to do with the way it affects them financially." 65 The degree of instability these children experience is, of course, associated with the degree of prior support. ${ }^{66}$ The economic support I focus on here could be financial or quasi-financial such as through groceries, gifts, amenities, and childcare.

Past analyses tend to underestimate the contributions of incarcerated parents. ${ }^{67}$ However, recent analysis of Fragile Families data has found that parental incarceration leads to "substantial and damaging" effects that exacerbate economic hardship for families, including eviction and inability to pay for material goods like healthcare. ${ }^{68}$ At least a portion of this stems from diminished resource contributions. ${ }^{69}$ Further analysis of the dataset strongly

63. Because the Fragile Families dataset allows comparisons amongst already-disadvantaged, similarly situated urban families, it is uniquely suited to show outcome differentials for families with incarcerated parents versus other disadvantaged families. And because it data is longitudinal, it also allows comparisons of conditions pre- and post-incarceration for the same family. Nevertheless, it cannot completely disaggregate disruptive factors that may simultaneously drive incarceration and other family disruptions. Because the core data for Fragile Families focus exclusively on unwed families (with married couples as a comparator sample) and not all inmate parents are unwed parents, conclusions drawn from the study may not track precisely; it may tend to underestimate the impact of parental incarceration because we would expect children to children receive more support from their married resident parents than from unmarried or nonresident parents.

64. BRAMAN, supra note 9, at 155 ("[B]ecause many prisoners are often a source of income in household prior to their arrest, the per capita income in that household . . . is also lowered whey they are removed."); Bruce Western \& Sara McLanahan, Fragile Families: Young Fathers with Incarceration Experiences, in 2 FAMILIES, CRIME AND JUSTICE, 309, 312 (Greer Litton Fox \& Michael L. Benson eds., 2000) ("The most obvious consequence of incarceration is its incapacitative effect... If the incarceration rate were lower, many of those currently in prison might otherwise have held jobs and contributed to the support of families.").

65. CLEAR, supra note 8, at 130 .

66. Western \& Wildeman, supra note 53, at 169.

67. See Bruce Western, Becky Pettit \& Josh Guetzkow, Black Economic Progress in the Era of Mass Imprisonment, in Invisible PUnishment: The Collateral ConseQuence OF Mass INCARCERATION 165, 165-69 (Marc Mauer \& Meda Chesney Lind eds., 2002).

68. Schwartz-Soicher, Geller \& Garfinkel, supra note 62 , at 461-67, 468 .

69. $I d$. at 470 . The living arrangements of inmates and their children prior to and post incarceration may vary depending on race, the age of the children and of the parents, and gender of the incarcerated parent. Holly Foster, Living Arrangements of Children of Incarcerated Parents, in CHILDREN OF InCARCERATEd Parents: Theoretical, Developmental, AND CliniCal Issues 127, 149-52 (Yvette R. Harris, James A. Graham \& Gloria J. Oliver Carpenter eds., 2010). 
suggests a causal link between parental incarceration and a significant reduction in financial support to children, and that this connection is unlikely due to extraneous factors. ${ }^{70}$

Ethnographic and quantitative studies show that many inmates "often provided material support (legal and illegal) for their families before they went to prison ... . This loss of support was almost never made up by the family."71 Loss of contributions is almost certain for any parent who prior to incarceration was a single parent or a co-parent in a two-parent household, or provided either primary care or financial support to their children as nonresident parents. Most incarcerated parents reported contributing to their children's well-being prior to incarceration, and thus their exit presents a direct loss. ${ }^{72}$

Of the 92 percent of parents in prison who are male, 54 percent reported providing primary financial responsibility prior to arrest regardless of whether they lived with their children. For the 8 percent of the prison parent population who are mothers, 52 percent reported providing primary financial support, even though in the month immediately preceding arrest, 44 percent did not live with their children. ${ }^{73}$ Thus, many parents who did not live with their children the month before their arrests nevertheless provided tangible support for their children. Of the mothers and fathers who did not contribute primary financial responsibility to their children, about a quarter each were nevertheless caregivers for their children. ${ }^{74}$ Forty-four percent of state and 52 percent of federal inmate parents lived with their children prior to arrest, and in that way, provided at least some amount of direct support. ${ }^{75}$ The aggregation of these statistics shows that only a small minority of both mothers and fathers in prison were neither the primary financial contributor nor caregivers for their children.

70. Amanda Geller, Irwin Garfinkel \& Bruce Western, Paternal Incarceration and Support for Children in Fragile Families, 48 DEMOGRAPHY 25, 42 (2011).

71. See ClEAR, supra note 8, at 130; see also Marcia J. Carlson \& Sara S. McLanahan, Fathers in Fragile Families (Princeton University Center for Research on Child Well-being, Working Paper WP0914-FF, May 11, 2009) (describing the types of formal and informal financial and quasi-financial contributions unwed fathers make towards their children).

72. See, e.g., KATHRYN EDIN \& LAURA LEIN, MAKING ENDS MEET 181-85, 227 (1997) (noting the underreported economic contributions of poor men to their families and children).

73. A part of this discrepancy can be explained by the fact that three-fourths of children of incarcerated mothers who were once their primary caretakers were already in foster care prior to their mothers' incarceration. See Glaze, Maruschak \& Mumola, supra note 14, at 42 . Forty-two percent of mothers in state prison identified grandmother as current caregiver. Eleven percent of mothers said care was through a foster home, agency or institution. For fathers, the figure was two percent. ld.

74. Glaze \& Maruschak, supra note 15 , at 17.

75. Id. 


\section{Parents in State Prison}

\begin{tabular}{|lr|}
\hline \multicolumn{2}{|c|}{ Mothers in Prison, Direct Support Prior to fncarceration } \\
\hline Primary Financial Responsibility & $52 \%$ \\
No Primary Support, but Lived with Child in Prior Month & $38 \%$ \\
Total & $90 \%$ \\
\hline
\end{tabular}

Fathers in Prison, Direct Support Prot to lncarceration Primary Financial Responsibility 54 No Primary Support, but Lived with Child In Prior Month $\quad 22 \%$ Total

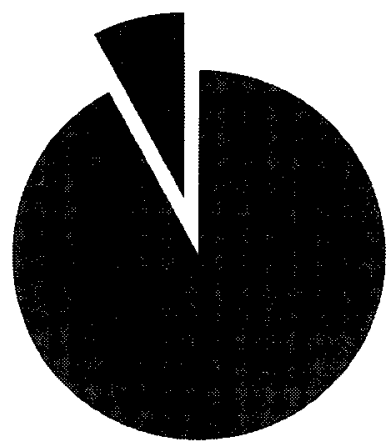

76

According to a recent multi-state study of recently released prisoners, about half the fathers reported primary care responsibilities for their minor children in the six months prior to their incarceration, and almost a third of the fathers had child support orders. Of those, about half said they made the support payments, though over 90 percent acknowledged they owed back child support. ${ }^{77}$ Children of parents like these lose the previous levels of economic support when their parents go to prison. ${ }^{78}$

Incarceration wreaks havoc on child well-being, even if the incarcerated parent did not live with the child prior to prison. Beyond direct and formal financial contributions, many incarcerated men provided informal support or in-kind support through childcare, home maintenance, or other avenues. ${ }^{79}$ Sociologists tracking low-income fathers conclude that "while many young fathers have trouble holding a job and may even spend time in jail, most have something to offer to their children." ${ }^{80}$ This is supported both from the men's own reports and corroborated by reports from the primary caregivers. ${ }^{81}$ Work

76. Figure adapted from Glaze \& Maruschak, supra note 15, at 6.

77. Pamela K. Lattimore, Danielle M. Steffey \& Christy A. Visher, Prisoner Reentry Experiences of Adult Males: Characteristics, Service Receipt, and Outcomes of Participants in the SVORI Multi-site Valuation, The Multi--Site Evaluation of the Serious And Violent Offender Reentry Initiative (December 2009). The Serious and Violent Offender Reentry Initiative (SVORI) was designed to improve outcomes for released prisoners. The study on the SVORI population included interviews with 1,700 parolees, 30 days pre-release and 3,9, and 15 months post-release. Id.at $\mathrm{v}$.

78. Furthermore, incarceration is a trigger event for parental separation. So while some parents may return from incarceration and contribute at previous levels, many will not partly because their relationship with the child's other parent has taken a turn for the worse. See SARA WAKEFIELD \& CHRISTOPHER WILDEMAN, CHILDREN OF THE PRISON BOOM 61 (2014).

79. See Joyce A. Arditti, Parental InCarceration and the Family 79-80 (2012); Edin \& LEIN, supra note 72, at 181-88; BRAMAN, supra note 9, at 156.

80. Irwin Garfinkel, Sara McLanahan \& Thomas L. Hanson, A Patchwork Portrait of Nonresident Fathers, in FATHERS Under FIRE: THE REVOLUTION IN ChILd SUPPORT ENFORCEMENT 39 (Irvin Garfinkel et al., eds., Russell Sage Found. 1998). See also Christopher Uggen, Sara Wakefield \& Bruce Western, Work and Family Perspectives on Reentry, in PRISONER REENTRY AND CRIME IN AMERICA 209, 211 (Jeremy Travis \& Christy Visher eds., 2005).

81. See ARDITTI, supra note 79 , at 79 . 
by sociologists Kathryn Edin and Laura Lein demonstrates that single-family households headed by women received support from cohabiting mates who assisted with childcare. ${ }^{82}$ Edin and Timothy Nelson observe in a new study of inner-city poor fathers that the parents provided financial support on an "as needed" approach, which in the researchers' ethnographic observation "seldom puts cash in the hands of the child's mother but is directly responsive to particular needs of the child." ${ }^{83}$ Anne Nurse's study of paroled young fathers in Northern California found that although most subjects became parents by accident or through very transient relationships, and very few married the mothers of their children, most were happy and proud to become fathers. ${ }^{84}$ About 80 percent said that prior to becoming incarcerated, they provided money or other kinds of assistance (food, supplies) to the mother of their children in preparation for the birth. ${ }^{85}$ Whatever support they gave, however, tended to be inconsistent; the men said it depended "on their child's needs in any given week." 86

Even for parents who did not contribute economically to their children prior to incarceration, their imprisonment is not necessarily a neutral event from the perspective of the child receiving resources. ${ }^{87}$ The trajectory of fatherhood is a long one, and the pre-incarceration level of support is not necessarily indicative of what that parent would have contributed in a different turn of events. Edin and Nelson note that "most fathers who have grown disconnected from their children are seldom satisfied with the scrap ends of fatherhood. For most, the desire to father actively —and claim the 'whole father experience'-is strong." 88 For many parents who end up in prison, the preincarceration level of support many not be an appropriate benchmark to evaluate their future contributions to their children had they not been in prison.

Finally, even for parents who did not provide and would not have provided economic support to their children prior to their incarceration, incarceration can still be significantly adverse for their children's financial needs, because there is a possibility that these parents could have changed course had their sentences been shorter. Edin and Nelson note that fathers' contribution to their children's lives is a dynamic model, which could be disrupted by a number of factors,

82. See EDIN \& LEIN, supra note 72 .

83. KATHRYN EDIN \& TIMOTHY NELSON, DOING THE BEST I CAN: FATHERHOOD IN THE INNER CITY 111 (2013).

84. NURSE, supra note 16, at 32-33. Nurse's subjects were participants in the Northern Region of the California Youth Authority, which supervises serious and repeat juvenile offenders in California. This finding is echoed by Edin \& Nelson's findings that many of these parents were extremely happy to have a child, even under disadvantaged circumstances.

85. NURSE, supra note 16, at 33-34.

86. Id. at 97 .

87. As the following subsections will show, even the exit of those parents confer economic disadvantage on their children. See infra Part II.B.2-5.

88. EDIN \& NELSON, supra note 83, at 189. 
including incarceration. ${ }^{89}$ In another study, Edin, Nelson and Rechelle Parranal document the possibility of prison as a transformative point for men who previously had no relationships with their children. ${ }^{90}$ They found that for "offenders whose lifestyle had created a wedge between himself and his family prior to ... incarceration can be a turning point. . . In some cases, fathers in this group use the experience of incarceration to rebuild severed ties with children."91 This suggests that for some parents, the impetus for providing support to their children may arise after they have already been committed to incarceration. The length of their remaining time in prison, however, prevents them from acting on their wishes to provide resources.

Though the negative impact of parental incarceration does not apply evenly to the children of all incarcerated parents, ${ }^{92}$ there is no doubt that there are severe and widespread collateral consequences of losing a parent to prison. The reduction in resources contributes to childhood economic insecurity. ${ }^{93}$

\section{Additional Costs that Families Bear from Parental Incarceration}

The loss of income and the instability triggered by incarceration poses deep strains on the remaining caregiver(s), such as the child's mother or grandparents. ${ }^{94}$ Not only does the incarceration remove a source of economic support for many families, but it also imposes additional financial burdens. "[T]he effects of incarceration ... are far more expansive than the lost earnings of offenders alone." ${ }^{, 95}$ Alternative effects are documented by a recent study based on Fragile Families data, which suggested that the exacerbation of material hardship for families of incarcerated parents stems in part from direct losses in support as well as the other parent's reduced capabilities as a result of incarceration. $^{96}$

Incarceration both "diminishes family income and . . . [increases] family expenses." $" 97$ The loss of the other parent as a romantic companion, a source of financial support, or an additional caregiver creates additional stresses and

89. Id. at $173-75$.

90. Kathryn Edin, Timothy J. Nelson \& Rechelle Paranal, Fatherhood and Incarceration as Potential Turning Points in the Criminal Careers of Unskilled Men (Insti. for Policy Research Working Paper No. WP-01-02, 2001).

91. Id. at 7 .

92. See Wildeman \& Western, supra note 53 , at 169.

93. While Edin and Nelson's interviews with inner-city fathers showed that some criticized the "emphasis on financial provision" as a cornerstone of fatherhood, and that they believed "spending money on children is nowhere as important as spending time," resource deprivation is a reality for these children and cannot be corrected absent intervention. See EDIN \& NELSON, supra note 83, at 142.

94. See ARDITTI, supra note 79, at 113.

95. BRAMAN, supra note 9 , at 157.

96. Schwartz-Soicher, Geller \& Garfinkel, supra note 62 , at 470.

97. Wildeman \& Western, supra note 53, at 166. 
costs on nonincarcerated caretakers. ${ }^{98}$ Furthermore, the costs associated with having an incarcerated family member-everything from civil forfeiture, to very costly phone calls, to co-payments on the inmate's health care-all take resources away from children. ${ }^{99}$

In an ethnographic study of women who were romantically involved with inmates at San Quentin prison, Megan Comfort documents some of the ways in which a partner's incarceration can cause severe resource strain. "Girlfriends and wives often send money and care packages, accept expensive collect phone calls, spend money traveling to visit inmates, and support their children."100 The rationales for doing so are complex. In one account, for example, Alice Goffman discusses the dilemma that many women face when police pressure them to provide information against their partners, and the resulting efforts to provide support to incarcerated partners as a way to "salvag[e] their moral worth in the wake of their betrayals," which are often aired out in public. ${ }^{101}$

In Comfort's study, half the women said they sent money, ranging from a few hundred dollars initially to weekly allowances. ${ }^{102}$ When considering the income levels that many of these families have, these marginal outlays are significant. Even if the incarcerated parent was completely delinquent in providing support and drained family resources before going to prison, his "stay in prison can simply shift the financial drain from maintaining the person on the streets to helping him cope in prison." 103

These are "women trying to hold families together when ties are weakened by prolonged absence; women attempting to manage the shame and stigma of incarceration; and women trying to prevent children from becoming casualties of the war on drugs." 104 These burdens, and the understandable failure to succeed at carrying them, in turn create more stresses on the entire family. The financial straits that deepen as a result of incarceration "tend[] to exacerbate all the other problems of intimacy, closeness, and reintegration back into the

98. Id.

99. See, e.g., Creasie Finney Hairston, Prisoners and Their Families: Parenting Issues During Incarceration, in PRISONERS ONCE REMOVED, 259, 265-66 (Jeremy Travis \& Michelle Waul eds., 2003) (noting the costs of collect calls and the cost of healthcare copays in prison). The Federal Communications Commission in 2013 voted to cap the amount that phone companies can charge for prisoners' calls. Phone companies have challenged this in federal court. The FCC's interim rates went into effect in February 2014, but the ultimate rates will depend on the D.C. Circuit's review. See Securus Technologies, Inc. v. FCC, No. 13-80 (D.C. Cir 2013). Moreover, this rule does not apply to in-state calls.

100. BRAHMAN, supra note 9, at 87; see also CLEAR, supra note 8 , at 132.

101. See GofFMAN, supra note 27 , at 75,82 .

102. COMFORT, supra note 36 , at 84 . See also other empirical accounts, such as ARDITTI, supra note 79 , at 110 , estimating monthly support at $\$ 75$.

103. ClEAR, supra note 8 , at 132 .

104. Beth Richie, The Social Impact of Mass Incarceration on Women, in INVISIBLE PUNISHMENT, supra note $67,136,147$. 
family and the community." 105 Incarceration of a child's parent led "many caregivers [to leave] their jobs after the incarceration and began receiving social welfare support." ${ }^{106}$ It also "saps the savings of grandparents." ${ }^{107}$ It is not difficult to trace the financial and material losses that lead to destabilized daily life: the loss of a caretaker and a provider of income and goods will lead to more stresses on the family's breadwinner. The results are diminished resources and heightened instability in the lives of their children. ${ }^{108}$

\section{Cumulative Loss in Ability to Contribute Due to Ex-Felon Status}

The analysis above has thus far only focused on the economic consequences for children created while their parents are in prison. Yet a large component of reduced support results from the erosion of their incarcerated parent's earning potential after release. ${ }^{109}$ The loss of employment and wageearning opportunities and access to public benefits and housing for ex-inmates directly maps onto a loss in capacity for ex-inmates to contribute to their children. ${ }^{110}$ The result is that "[w]hile prison removes men from families, the echo of incarceration continues well after release from prison." "11!

The loss of future parental contribution based on criminal record statusfelt particularly acutely by black and younger ex-felons ${ }^{112}$-is an important but often-overlooked mechanism by which parental incarceration confers disadvantage on children. The cumulative effect of loss in parental income as a result of incarceration can be discounted back in time; this figure would represent the full amount of financial loss to the child as a result of parental incarceration.

Data demonstrates that incarceration is an independent driver of lower employment and income attainment. ${ }^{113}$ Though "convicted felons often enter prison with a history of unemployment, low educational attainment, and few marketable job skills," 14 research shows that incarceration confers additional barriers to employment and wage-earning beyond the existing problems of too

105. R. Robin Miller, Various Implications of the "Race to Incarcerate" on Incarcerated African American Men and Their Families, in IMPACTS OF INCARCERATION ON THE AFRICAN-AMERICAN FAMILY 1, 8 (Othello Harris \& R. Robin Miller eds., 2003).

106. ARDITTI, supra note 79, at 110 .

107. BRAMAN, supra note 9 , at 156.

108. See, e.g., Schwartz-Soicher, Geller \& Garfinkel, supra note 62, at 469-70.

109. Devah Pager, Marked, 108 AM. J. SoC. 937, 960-62 (2003).

110. Western \& McLanahan, supra note 64, at 17.

111. Id.

112. See WESTERN, supra note 43, at 115-25. Younger inmates are also more likely to be parents of dependent children.

113. See, e.g., Geller et a1., Parental Incarceration and Child Well-being, supra note 62, at 2.

114. Uggen, Wakefield \& Western, supra note 80, at 211. 
few opportunities. ${ }^{115}$ Using data from the National Longitudinal Survey of Youth (NLSY) from 1983 to 2000, Bruce Western explores whether prison reduces the economic prospects of ex-offenders, or if these individuals' lower prospects are "simply a predictable result of skill deficiencies and a propensity for antisocial behavior." $" 116 \mathrm{He}$ found that incarceration reduces annual wages of Whites, Hispanics, and Blacks (by 9 percent, 10 percent, and 8 percent, respectively), and that ex-felon status was associated with less continuous employment for Blacks and Hispanics. ${ }^{117}$ Incarceration reduces total lifetime earnings by 40 percent for individuals. ${ }^{118}$ And across groups, it is responsible for a 4 percent increase in the poverty rate amongst Blacks $(2.7$ percent increase in poverty rate for Hispanics and 1 percent for Whites). ${ }^{119}$ Western adds that the deficit in employment prospects for ex-felons "produces economic conditions for continued crime," 120 which may lead to continued diminished or no earnings if the individual is apprehended.

There are two major mechanisms by which former incarceration status leads to lower earnings: employers' unwillingness to hire ex-felons and the erosion of skills and ties while inmates are in prison. ${ }^{121}$ On the first factor, Devah Pager's experiment separates the specific effect of the stigma of criminal history from other background drivers of employment outcomes for ex-felons. ${ }^{122}$ In the study, black and white men with identical educational records and work experience as well as physical presentation were randomly assigned criminal records and applied for jobs. ${ }^{123}$ In auditing 350 employers in the initial application process, the study found that both race and incarceration status were significant drivers of employment prospects. Incarceration status reduced both black and white applicants' likelihood of being called back. Whites with no criminal record were called back 34 percent of the time,

115. See, e.g., William Julius Wilson, When WORK DisapPEARS 25-27 (1996) (documenting drops in real wages and availability of jobs, as well as discrimination, residential segregation, and the shift away from industrial labor).

116. WESTERN, supra note 43 , at 116 .

117. Id. at 124 .

118. Id. at 126 .

119. Id. at 127 .

120. Id. at 130.

121. See Uggen, Wakefield \& Western, supra note 80 , at 220 ; Bruce Western, Jeffrey R. Kling \& David F. Weiman, The Labor Market Consequences of Incarceration, 47 CRIME \& DELINQUENCY 410, 412 (2001); Wildeman \& Western, supra note 53, at 165-66.

122. Pager, supra note 109 , at 937 . Pager's experimental design improves on previous resume experiments by expanding the types of jobs and making clearer to the employer the race of the applicant. Id. at 943 . There are also explicit regulatory barriers to employment for ex-felons for some jobs, which is not "stigma" per se but nevertheless limit the scope of jobs available. See Patricia M. Harris \& Kimberly S. Keller, Ex-Offenders Need Not Apply: The Criminal Background Check in Hiring Decisions, 21 J. CONTEMP. CRIM. JUST. 6 (2005); Harry J. Holzer, Steven Raphael \& Michael A Stoll. Employment Barriers Facing Ex-Offenders, URBAN INSTITUTE REENTRY ROUNDTABLE: EMPLOYMENT Dimensions of REENTRY: UNDERSTANDING THE NEXUS BETWEEN PRISONER REENTRY AND WORK $15-$ 16 (2003), http://www.urban.org/UploadedPDF/410855_holzer.pdf.

123. Pager, supra note 109 , at $946-48$. 
compared to 17 percent for Whites with ex-felon status. Blacks without a criminal record were called back 14 percent of the time, faring even worse than white ex-felons. Blacks with a criminal record faced the biggest hurdle, getting called back only 5 percent of the time. ${ }^{124}$ Pager also points out that failure to obtain employment has knock-on effects. As time passes, the negative employment outcomes due to race and incarceration status "then exacerbates the manifestation of stigma; the cumulative disadvantage that accrues to such individuals sets into motion a self-reinforcing cycle." 125 The recognition of the stigma of incarceration has led to "Ban the Box" campaigns to eliminate employer application forms that ask for criminal record status at early stages. ${ }^{126}$ Nevertheless, incarceration still vastly reduces employment prospects, which in turn reduces incarcerated parents' ability to contribute financially to their children's well-being.

A second way in which prison reduces employment prospects is through the erosion of job skills and social ties while in prison. Prison disrupts and reconfigures the inmate's social universe, "replacing social connections to legitimate employment" if that ever existed. ${ }^{127}$ Thus, the reduction in social capital that follows is a negative driver of employment opportunity ${ }^{128}$ as inmates lose contacts that would lead them to legitimate employment. In addition, "[t]ime out of employment prevents the acquisition of skills obtained by others who remain continuously employed ... [and] behaviors that are adaptive for survival in prison are likely to be inconsistent with work routines outside." 129 A stronger formulation is that prisons are themselves criminogenic, not only by reducing re-entry opportunities afterwards but by creating "schools of crime" for inmates: by acquainting them with other criminals in prison and by connecting prisoners to criminal opportunities afterwards. ${ }^{130}$ All in all, though the specific causal effects of prison on the prisoner's internal capacities and attitudes are difficult to document as the ex-inmate immediately begins to accumulate post-prison adjustment, ${ }^{131}$ it is clear that imprisonment is likely to

124. Id. at $955-59$

125. Devah Pager, Marked 149 (2004).

126. See Ban the Box, ALL OF US OR NONE, http://www.allofusornone.org/campaigns/ban-the-box. This campaign has met some success in many localities across the country. Ban the Box: Major U.S. Cities and Counties Adopt Fair Hiring Policies to Remove Unfair Barriers to Employment of People with Criminal Records, NAT'L EMPL. L. PROJ. (Nov. 2012), http://www.nelp.org/page//SCLP/2011/

CityandCountyHiringInitiatives.pdf.

127. Uggen, Wakefield \& Westem, supra note 80, at 221.

128. See Mark Granovetter, Getting a Job: A Study of Contacts and Careers (2d ed. 1985).

129. Id.

130. Shadd Maruan \& Hans Toch, The Impact of Imprisonment on the Desistance Process, in PRISONER REENTRY AND CRIME IN AMERICA, supra note 114, at 139, 152-57 (citing Donald Clemmer's coining of the term "prisonization"). For other accounts of prisonization, see DONALD CLEMMER, THE PRISON COMMUNITY (1940). For an influential account of the culture of deprivation sustained by prisons, see GRESHAM SYKES, SOCIETY OF CAPTIVES (1965).

131. See Maruan \& Toch, supra note 130 , at 157. 
reduce the ability of the inmate to financially contribute to his children postrelease.

In addition, ex-felon status often creates legal barriers for incarcerated parents' access to public benefits and housing, which compounds whatever wage-earning problems they already face. ${ }^{132}$ For example, federal law bars individuals with felony drug convictions from receiving TANF and food stamp benefits unless their states affirmatively opt out of the ban. ${ }^{133}$ Difficulty finding a job, as discussed above, would also make it hard for these individuals to meet the TANF work requirements. ${ }^{134}$ Subsidized housing programs follow a onestrike-and-you're-out policy with criminal records, making it extremely difficult for poor parents who have criminal records to find affordable housing. ${ }^{135}$ These factors all culminate in the loss of earnings ${ }^{136}$ and diminish the incarcerated parent's inability to contribute economically to their children post-release.

The fact that ex-inmates have diminished income opportunities has major implications for an incarceration insurance program that asks parents to pay back. I discuss those considerations in depth in Part IV. However, the very fact of this diminished capacity - along with the direct incapacitation of parental contribution from incarceration and the high costs of having a child's parent in prison for existing caretakers - strongly supports the proposition that parental incarceration is a unique causal driver of childhood disadvantage above and beyond those conferred by adverse background conditions alone.

\section{Beyond Economic Instability: Incarceration's Other Harms}

So far, we have focused on economic losses because they are the harms that virtually always accompany parental incarceration and are the harms most directly addressed by the proposal for incarceration insurance. However, there are a host of noneconomic harms to children that can result from parental incarceration. Some of these harms are just as important, if not more so, than resource deprivation alone. Though the proposal for incarceration insurance does not address these harms head-on, it is important to understand them in situating a policy tool amongst other reforms.

Numerous studies find associational relationships between parental incarceration and nonphysical adverse childhood outcomes, including antisocial

132. See Amy E. Hirsch et al., Every Door Closed: Barriers facing Parents with CRIMINAL RECORDS (2002), available at http://www.clasp.org/admin/site/publications_archive/ files/0092.pdf.

133. See id. at 2-3.

134. See id.

135. See id. at 41-43

136. See Westcrn, Kling \& Weiman, supra note 121 , at 424 (reviewing a swath of sociological studies to conclude that "serving time in prison can diminish an individual's eamings but not necessarily employment prospects"). 
and aggressive behavior, lower academic achievement, emotional fragility and mental problems, and future criminal activity. ${ }^{137}$ They corroborate the direct empirical finding that children whose fathers go to prison are more disadvantaged compared to similarly situated children whose fathers do not go to prison. ${ }^{138}$ In general, the link between parental incarceration and childhood disadvantage is supported by evidence of aggregation of risk factors:

The most consistent finding in research on children of incarcerated parents is that they are exposed to a greater total number of risk factors than other children. In other words, as a group, children of incarcerated parents are not just more likely to be exposed to parental substance abuse or domestic violence or inadequately educated parents or family disruption or any other single risk factor associated with parent criminality and incarceration. ${ }^{139}$

Longitudinal studies have also documented direct linkages between parental incarceration and childhood disadvantage. A review of ten longitudinal studies on the effects of parental incarceration corroborates the hypothesis that the risk for behavioral and mental health problems possibly increases with parental incarceration. ${ }^{140} \mathrm{~A}$ new study uses longitudinal and cross-section analysis of Fragile Families data to increase confidence in the proposition parental incarceration is a unique driver of childhood disadvantage, by finding

137. For existing studies on the non-financial effects of parental incarceration on children, see ARDITTI, supra note 79, at 101-09; Amanda Geller et al., Beyond Absenteeism: Father Incarceration and Child Development, 49 Demography 49, 51 (2011) [hereinafter Geller et al., Beyond Absenteeism] (finding heightened behavioral and developmental problems in children in Fragile Families that have incarcerated parents); Geller et al., Parental Incarceration and Child Well-being, supra note 62, at 119697 (demonstrating that children with fathers in prison face more severe economic, family, and housing problems than their counterparts); Denise Johnston, Effects of Parental Incarceration, in CHILDREN OF INCARCERATED PARENTS 1995, supra note 16, at 59 (documenting psychological and developmental effects); Sara S. McLanahan \& Marcia J. Carlson, Welfare Reform, Fertility and Father Involvement, 12 FUTURE OF CHILD. 147 (2002) (using Fragile Families data, showing that incarcerated fathers are more likely than non-incarcerated fathers to be violent, African-American, less educated, and exposed to drug abuse); Joseph Murray, David P. Farrington \& Ivana Sekol, Children's Antisocial Behavior, Mental Health. Drug Use, and Educational Performance After Parental Incarceration: A Systematic Review and Meta-Analysis, 138 PSY. BULL. 175, 190 (2012) (performing a meta-analysis of 40 existing studies and finding that rigorous studies tend to point to a connection between parental incarceration and later antisocial behavior); Christopher Wildeman, Paternal Incarceration and Children's Physically Aggressive Behaviors, 89 SOC. FORCES 285 (2010). See also Joseph Murray \& David P. Farrington, The Effects of Parental Imprisonment on Children, 37 CRIME \& JUST. 133, 172 (2008) (surveying empirical studies).

138. See Geller et al., Parental Incarceration and Child Well-being, supra note 62, at 1200 (finding the associational relationship after isolating extraneous factors, based on Fragile Families data).

139. Phillips, supra note 16 , at 19.

140. See Joseph Murray, Longitudinal Research on the Effects of Parental Incarceration on Children, in CHILDREN OF INCARCERATED PARENTS 2010, supra note 12, at 55, 69. Though these studies, like most others, are unable to "isolate the causal effects of incarceration from the confounding effects of family disadvantage," Geller et al, Beyond Absenteeism, supra note 137, at 52. Yet, they contribute to an understanding of the severity of disadvantage associated with parental incarceration. 
that differences in childhood aggression in children with incarcerated fathers are at least partially causal and remain significant after scenario-testing. ${ }^{141}$ The study separated the developmental effects for Fragile Families children with incarcerated fathers and those who did not, and distilled away the chances that the differences in these effects by confounding family variables. It also compared the effects of paternal incarceration against the effects of other forms of paternal absence and found that "paternal incarceration has significant and damaging consequences for the socioemotional well-being of young children." 142 Specifically, there is a "robust relationship between incarceration and child aggression," 143 after controlling for many variables, such as parents" relationship status, income, maternal education, and other forms of paternal absence. The study also found that children of incarcerated parents exhibited these behavioral problems more starkly after incarceration. ${ }^{144}$ Furthermore, the study found that the effects are strongest for children whose parents resided with them before incarceration, but is still significant for nonresidential parents. ${ }^{145}$ The study also found a similar relationship between paternal incarceration and attention problems in the children, though the results were not as significant. $^{146}$

There are two overall mechanisms that can frame the specific symptoms identified by researchers. First, the removal of a parent through incarceration is a form of disruption that hampers the child's development. ${ }^{147}$ The result of this disruption will vary according to many other confounding factors. Second, the departure of a parent is damaging to attachments that children have with their parent, and the severance of this link creates breakdowns in socio-emotional functioning. Young children "not only suffer separation distress and anxiety but also setbacks in the quality of their next attachments, which will be less trustful." ${ }^{148}$ For older children, the problem may manifest in the form of feeling rejected and subsequently feeling "[r]esentment towards the adults who have

141. See Geller et al., Beyond Absenteeism, supra note 137, at 62-68.

142. Id. at 71 .

143. Id.

144. See id. at 59.

145. See id. at 72 .

146. See $i d$. at 68 . There was no significant relationship between paternal incarceration and other child development issues, such as verbal ability, internalization of problems, and health (as reported by the child's mother). In addition, the results of a forthcoming study suggest that maternal incarceration may have null effects on children's behavioral issues. See Christopher Wildeman \& Kristin Tumey, Positive, Negative, or Null? The Effects of Maternal Incarceration on Children's Behavioral Problems, 51 DEMOGRAPHY 1041,1064 (2014).

147. See Joseph Goldstein, Anna Freud \& Albert J. Solnit, Beyond the Best Interests of THE ChILD, 32 (1973) [hereinafter GOLDSTEIN, FREUd \& SOLNIT, BEYOND BEST INTERESTS] (noting that "changes in the external world" disrupt the developmental process of children, who are also undergoing internal changes).

148. Id. at 33 . 
disappointed them in the past makes them adopt the attitudes of not caring for anybody." 149

Furthermore, the noneconomic effects of separation are not confined to the socio-emotional realm. Paul Tough documents powerful, emerging scientific evidence that demonstrates that adverse childhood experiences--parental incarceration being one of them-have strong associations with long-lasting physical and developmental effects. ${ }^{150}$ Scientists tracking adverse childhood experience ("ACE") factors, "from overcrowding to poverty to family turmoil," 151 have found "a surprisingly linear dose-response model: the higher the ACE score, the worse the outcome on almost every measure from addictive behavior to chronic disease." 152 A series of studies that dissected various contributing factors concluded both in the strength of the relationship, and in findings that ACE factors also had pathological effects, ${ }^{153}$ where the "key channel through which early adversity causes damage to developing bodies is stress," or what scientists call "allostatic load"-the cumulative stressor effects that children bear. ${ }^{154}$ The higher the ACE score, the higher the allostatic load on children, and the more susceptible they are to adverse health and developmental outcomes: everything from heart disease, addiction, poor concentration, and other impaired executive-function skills. ${ }^{155}$ These effects are caused by the onset of adverse childhood experiences, but they are also compounded by the loss of "secure attachment relationships with caregivers," which can "buffer the effects of stress and trauma." parental incarceration can create a parallel conduit to negative physical effects in children later on, because it constitutes both the very environmental stress trigger that builds on allostatic load and the deprivation of a buffer effect that could have alleviated other environmental stressors for already-disadvantaged children. ${ }^{157}$

The ways in which socioemotional and developmental damage occurs varies depending on the child, the parent, and many other contextual factors. Therefore, there is not-and nor should we expect there to behomogeneity. ${ }^{158}$ In fact, "even among groups of prisoners' children selected for

149. Id. at 34 .

150. See Paul Tough, How ChILdREn SuCceEd 32 (2012).

151. Id ; see also THE ADVERSE CHILDHOOD EXPERIENCES STUDY, http://www.acestudy.org [hereinafter ACES STUDY].

152. TOUGH, supra note 1507 , at 10 .

153. See id. at 11.

154. Id at 12-13.

155. Id at 11-13, 1992.

156. See id. at 192.

157. See id.; ACES STUDY, supra note 1518.

158. See Susan D. Phillips \& James P. Gleeson, What We Know Now that We Didn't Know Then about the Criminal Justice System's Involvement in Families with whom Child Welfare Agencies Have Contact 4 Center for Social Policy and Research, Jane Addams College of Social Work, UNIVERSITY OF ILLINOIS AT CHICAGO (July 2007), http://www.fenetwork.org/reading/ 
study because of their emotional, behavioral or disciplinary problems, few of the children had problems in every area and all of the children were performing adequately in one or more areas." 159

This proposal focuses on material deprivation, precisely because it is difficult to identify and attribute all of these other negative outcomes directly to parental incarceration. ${ }^{160}$ Granting children incarceration insurance will probably not go very far in counteracting socioemotional damage or physical harm due to stress, but it may help by raising the standard of living for children and reduce the total impact of disadvantage.

\section{Confounding Variables and the Myth of the "Bad Parent"}

The above research documents the phenomena that parental incarceration visits on children both tangible, economic harm and intangible, socioemotional and long-term physiological detriment. An important counterargument against the very idea that parental incarceration is harmful to children, however, posits that parents who are sent away to prison are so dangerous or so deeply entrenched in harmful criminal activity that their children are better off without their influence. This is an important question to address, and may ring true for a very limited subset of incarcerated parents. Because incarcerated parents and non-incarcerated non-resident parents are similar in many ways, ${ }^{161}$ poor outcomes identified by scholars may be picking up the effects of general disadvantage rather than imprisonment. ${ }^{162}$ However, ample evidence supports the proposition that the vast majority of children of incarcerated parents are made worse off in both tangible and intangible-but wholly real-ways as a result of their parents' incarceration. As Fragile Families data analysis demonstrates through cross-sectional control tests, reductions in family income after parental incarceration is not "simply due to their being 'bad' fathers" in

what_we_know_now.pdf.

159. Johnston, supra note 16 , at 65 .

160. The wounds that incarceration inflicts are deep and some are even less visible and traceable than the long-term developmental and psychological effects on children described above. See BRAMAN, supra note 9 , at 10 (describing families' own beliefs that incarceration is responsible fraying kinship bonds and socially destructive behavior).

161. See Seymour, supra note 50, at 474 (describing similarities between the two populations, but noting that "they are different in ways that make them and their families a challenging population to serve"); see also Kathi J. Kemper \& Frederick P. Rivara, Parents in Jail, 92 PEDIATRICS 261, 264 (1993).

162. See Christopher Wildeman, Mass Parental Imprisonment, Social Policy, and the Future of Inequality in America, in CHILDREN OF INCARCERATED PARENTS 2010, supra note 12, at 303, 309 (cautioning against drawing causal conclusions too quickly and suggesting using experimental macrolevel data in future studies to tease out the causal mechanisms); Danielle H. Dallaire, Incarcerated Mothers and Fathers: A Comparison of Risks for Children and Families, 56 FAM. RELATIONS 440, 441 (2007) (noting that these children "may be particularly vulnerable to poor outcomes because of their exposure to an array of background, contextual, or sociodemographic factors"); Kennedy, supra note 15, at 93 (noting that negative child outcomes may occur "at least partially ... from the ill effects of living in poverty"). 
general but rather due to the distinct disadvantages conferred by prison on ability to access the labor market, relationship quality, and removal from their children. $^{163}$

Furthermore, whatever distinctions exist between convicted criminals and noncriminals, there is little reason to believe that such distinctions are particularly good indicators of parenting ability. Parents who are incarcerated but have no prior neglect or abuse problems are not necessarily bad parents, ${ }^{164}$ and they are likely good enough parents from the child's point of view or better than no parent at all.

This is not to say that some children are probably better off with their parent in prison rather than wreaking havoc on their daily lives through abuse or other means. But most inmates ${ }^{165}$ are in prison for crimes that do not relate directly to their desire or ability to care for their children. ${ }^{166}$ The state does not automatically remove parental rights upon incarceration precisely for that reason. ${ }^{167}$ In fact, parenting classes in prisons operate on the premise that "[p]eople can be bad citizens but good parents." "168 It is also the impetus behind efforts to grant greater visitation opportunities between parents and their children. $^{169}$

In fact, behavior that lands many disadvantaged parents in prison may have little bearing on parenting. For example, some incarcerated parents are young teenagers who are earning income for the first time. Others are unable to find other work, or are those who provide payments to their children through underground income because they are unable to shoulder wage garnishments on

163. Geller, Garfinkel \& Western, supra note 70, at 43-44.

164. See, e.g., ChILDREN OF INCARCERATEd PARENTS 1, supra note 16, at 7-8; Kennedy, supra note 15 , at 90 ("Many parents who find themselves in prison are not necessarily bad parents by virtue of their incarceration and may, in fact, be good and effective parents. One cannot generalize about the parenting skills of incarcerated parents. ..").

165. The vast majority of parents in prison are incarcerated for nonviolent offense. Those who commit abuses against their partners or children often get their parental rights terminated upon incarceration for those offenses. See Kennedy, supra note 14, at 96-97 (describing state statutes that predicate parental rights termination on certain crimes). But see Kemper \& Rivara, supra note 161, at 262 (charting drug abuse behavior in parents in jails).

166. For a discussion of policies of removal of parental rights for incarcerated parents, see Mitchell, supra note 14.

167. See Santosky v. Kramer, 455 U.S. 745, 753 (1982); Troxel v. Granville, 530 U.S. 57, 62 (2000). When the state does remove parental rights of incarcerated parents, such as through petitions to terminate parental rights (TPR) through the Adoption and Safe Families Act of 1997, Pub. L. No. 10589, 111 Stat. 2115 (codified as amended in scattered sections of 42 U.S.C.), it does so because the parent's crime was against the child or because the child has been in foster care for an extended period of time. The TPR process has also been criticized for its structural inequalities with respect to race and class. See generally Mitchell, supra note 14.

168. BERNSTEIN, supra note 3 , at 96.

169. See id. ("Relationships between fathers and the mothers of their children have a profound effect on kids. Contact between incarcerated fathers and their children can have a positive impact on both."). 
licit income. ${ }^{170}$ Both may legitimately believe that illicit markets are the only viable means of making a living. ${ }^{171}$

The rise in incarceration rates has largely been due to the erosion of economic opportunities in the inner cities and more draconian criminal justice policies, ${ }^{172}$ not a rise in some inherent antisocial nature of low-income people. As the rate of incarceration has grown, partially driven by possession crimes and heavy policing in certain areas, the prison population "has come to resemble more closely the general population" in certain areas. ${ }^{173}$ The distinction between which parents end up in prison and which ones do not is often one of structural policies and inequalities in enforcement rather than dangerousness. The distinction between which parent stays in prison for longer, away from their child, is often set by circumstances unrelated to parental ability but rather to events prior to or at arrest, or the operation of the legal system.

Indeed, the racial data makes it hard to forge the conclusion that imprisoning a parent generally removes a negative influence in children's lives. To believe that children are no worse off as a result of their "bad parents" going to prison, one would have to believe either that people from communities that have higher incarceration rates are generally bad parents, or that those convicted of crimes are different from noncriminals in a meaningful way that generally hews closely to bad parenting. ${ }^{174}$ It would mean believing that half of black children with high school dropout fathers are better off with their fathers in prison. The line that incarceration draws mostly includes people who have done wrong things, but it is not a close match to the line demarcating people who are not adequate parents.

The evidence supports the conclusion that incarcerating a parent causes actual disadvantage to his child, even though the parent was engaged in

170. See Ronald B. Mincy \& Hillard Pouncy, Delivering Dads: Paternalism, Child Support Enforcement, and Fragile Families, in THE NEW PATERNALISM 130 (Lawrence M. Mead ed., 1997) (noting that issues of illegal income and garnishment for fathers paying, or trying to pay, child support); Hillard Pouncy, Towards a Fruitful Policy Discourse about Less-Educated Young Men, in BLACK MALES LEFT BEHIND 293, 301 (Ronald B. Mincy ed., 2006) (noting that efforts to "empower" young poor men did not go far because barriers to the job market still left them unemployed). Mincy and Pouncy point out that in the period between 1979 and 2000, "employment rates of young, less-educated black men fell by 16 percentage points while those of comparable young black women rose by 1 percentage point." Ronald B. Mincy \& Hillard Pouncy, Op-Ed: Fatherhood Programs May Lift Up Young Men, BALT. SUN, Apr. 17, 2006.

171. See Braman, supra note 9, at 154-55; MiChaEl. TONRY, ThInkING ABout CRIME: SENSE And Sensibility IN AmERICAN PEnAl Culture 13 (2004) ("To many disadvantaged inner-city American teenagers, for example, drug dealing, in comparison with other available options, appears to be a sensible and relatively low-risk way to earn money and improve their lives."); WILSON, supra note 115; Pager, supra note 109.

172. See WESTERN, supra note 43, at 109-110, 130; Wildeman \& Western, supra note 53, at 159.

173. Wildeman \& Western, supra note 53 , at 163.

174. One might also wonder if the exit of a crime-involved parent may usher in an opportunity for a "better" social parent as a replacement. However, there is no evidence that mothers' repartnering reduces material hardship for the family. See Schwartz-Soicher, Geller \& Garfinkel, supra note 62, at 469. 
unlawful behavior and could have chosen a better path. The relevant basis of comparison is what would have happened without the parent's incarceration. Unless the would-be incarcerated parent exerts such a detrimental effect on the child's life that we as a society would want to remove his parental status even absent his incarceration, the argument that his incarceration is not a true deprivation for his children seems to fall flat. Even though some parents may exert some bad influences on their children, the forcible removal of that parent from their children's life does not "offer such children something better. . . . By its intrusion the state may make a bad situation worse; indeed, it may turn a tolerable or even a good situation into a bad one." 175

Moreover, the very act of separation from even rather imperfect parents can be damaging to children. ${ }^{176}$ The bonds that children form with their parents-even those who are not around all the time, and even those "with impoverished or unstable personalities," nevertheless can lead to "extremely painful" severances. ${ }^{177}$ After all, being "forced to dismantle existing emotional ties . . . is no easy task for any human being. Children are especially unequipped for such losses." 178 That parents may have exerted bad influences does not necessarily figure into their children's world view and thus is often difficult to account for in the children's view of trauma. After all, "[f]or the child who is the innocent victim of such traumatic happenings," it does matter much why the reassignment is happening external to the relationship. ${ }^{179}$ The state should evaluate the child's well-being based on harm avoidance, and refrain from making sweeping long-term conclusions. ${ }^{180}$

$* * *$

This section demonstrated that relative to the baseline of child well-being prior to parental incarceration and relative to similarly situated families without incarcerated parents, the advent of parental incarceration puts children at risk of a special and distinct form of economic insecurity and other negative outcomes. The proposal for incarceration insurance aims primarily at the three pathways of material economic deprivation.

175. Joseph Goldstein, Albert J. SOlnit, SONJA Goldstein, THE Best Interests of the CHILD: THE LEAST DETRIMENTAL ALTERNATIVE 92 (1998).

176. See Seymour, supra note 50, at 6 (noting that children of incarcerated parents may have other "therapeutic" needs stemming from trauma and stigma of the involuntary removal of a parent).

177. GOLDSTEIN, FREUD \& SOLNIT, BEYOND BEST INTERESTS, supra note 147, at 19-20.

178. Goldstein, Freud \& SOlNit, BeFore BeSt INTERESTS, supra note 32, at 53-54.

179. Id.

180. See id. at 52 ("In the long run, the child's chances will be better if the law is less pretentious and ambitious in its aim, that is, if it confines itself to the avoidance of harm and acts in accord with a few, even if modest, generally applicable short-term predictions."). 


\section{The Severity of Parental Incarceration Disadvantage}

While the previous subsection explicated the causal mechanisms of how parental incarceration reduces resources to children, this subsection is concerned with the severity of that disadvantage. Besides demonstrating that parental incarceration is a unique driver of negative consequences for child well-being, it is important to understand whether these consequences are marginal or severe, though the previously exposition of evidence hints at the latter.

Parental incarceration is generally accompanied by an increase in child poverty. An analysis of childhood poverty through the Panel Study of Income Dynamics found that rate of children living in poverty increases from 22 percent to 31 percent in the years following their fathers' incarceration, and does not diminish significantly in the first years after his release. ${ }^{181}$ Family income on average decreased by $\$ 8,726$, or 22 percent. ${ }^{182}$ Much of this is directly attributable to incarceration. Fragile Families data analysis reveals that fathers with histories of incarceration contributed on average $\$ 1,300$ less per year than never-incarcerated fathers. ${ }^{183}$ This represents a quarter of the average contribution in prior years for the families in the sample ${ }^{184}$-in other words, a significant amount. This figure reflects the deprivation of income due to parental incapacitation while incarcerated, as well as the decline in income after reentry due to labor market reactions. While the study did not account for inkind support, ${ }^{185}$ the direct financial contribution picture is enough to show that the incarceration disadvantage is severe.

The effects of economic insecurity on children's physical, educational, emotional, and social development are very real and documented at length by researchers generally. More specifically, analyses of Fragile Families data have specifically shown that children of incarcerated fathers experience greater material hardship as measured by incidents such as failure to pay for food, housing, gas and electric utilities, doctors' visits, and telephone service. ${ }^{186}$ In turn, deprivation of food, shelter, healthcare, and other material goods have clear impacts on child well-being both in the short term and long term. ${ }^{187}$

181. ARDITTI, supra note 77 , at 110.

182. Id.

183. Geller, Garfinkel \& Western, supra note 70, at 39.

184. Id. The study also found that newly incarcerated fathers contribute on average $\$ 1,700$ less than their counterparts in the first year of the study. $I d$.

185. Id. at 45 .

186. See Schwartz-Soicher, Geller \& Garfinkel, supra note 62 , at 454,468 .

187. See, e.g., Elizabeth T. Gershoff et al., Income is Not Enough: Incorporating Material Hardship into Models of Income Associations with Parenting and Child Development, 78 CHILD DEV'T 70 (2007); Robert C. Whitaker, Shannon M. Phillips \& Sean M. Orzol, Food Insecurity and the Risks of Depression and Anxiety in Mothers and Behavior Problems in Their Preschool-Aged Children, 118 PEDIATRICS 859 (2006). See also supra Part II.B.4 (documenting the effects of poverty and other stressors on later health problems). 
Recent research has found that the recent incarceration of a parent increases the likelihood that a child experiences homelessness. ${ }^{188}$

One point in particular is worth emphasizing here: for poor children, the marginal cost of losing support due to parental incarceration often has acute and dramatic consequences. Sociologists document the sentiment among family members that

loss of income in the family negatively [due to incarceration] affects the family because the mother cannot support the family as well . . . [o]ne woman said, 'so when that father is pulled away, that leaves him [the child] depending solely on the mother who cannot give him sufficient of what the father was giving him.' An older woman who works in the neighborhood said she sees kids going hungry when the father goes to prison. ${ }^{189}$

Because poor families never had much to make ends meet in the first place, the loss of even a marginal amount of support due to a parent's incarceration can have a dramatic impact on the child.

Another way to estimate the severity of withdrawal of support due to parental incarceration is to examine the impact of child support on poor families. The experiences of families whose parents do not contribute child support can parallel those of families with an incarcerated parent. Studies about the impact of child support show that because poor men and poor women often have children together, and because poor women have limited sources of income, "nonresident fathers' economic contributions through child support play an important role in helping children to avoid poverty." 190 Numerous studies document the ways in which child support reduces child poverty through direct transfers of wealth: in reduction of the poverty rate in families receiving child support, and in reduction of the poverty gap for those who are still not lifted out of the zone of poverty. ${ }^{191}$

Loss of emotional and social support is important, but the loss of income and quasi-financial contributions is critical and severe. As three prominent researchers of child support explain:

A wide body of social science theory suggests that increasing the economic resources of custodial mothers will increase investments in

188. WAKEFIELD \& WILDEMAN, supra note 78 , at 124. The researchers disaggregated parental incarceration from other potential destabilizing familial factors to find that at least two-thirds of the effect on homelessness probability is driven by parental incarceration alone. Id. at 126-27.

189. See CLEAR, supra note 8 , at 131 (brackets in quotation in original).

190. See, e.g., Maria Cancian, Daniel R. Meyer \& Eunhee Han, Child Support: Responsible Fatherhood and the Quid Pro Quo, 635 ANNALS AM. ACAD. POL. \& SoC. SCl. 140 (2011).

191. See id. (citing extensive literature). 
children ... There is also a growing body of empirical research linking parents' economic resources to children's well being and reporting that children who live in non-intact families are less successful than children who live in intact families, and that much of the difference is due to differences in income. ${ }^{192}$

Of course, the degree to which parent's incarceration is harmful for his children depends in part on what the parent-child relationship was like before incarceration. ${ }^{193}$ The severity of the impact of parental exit will vary upon a number of factors, including:

[T] he age at which the parent-child separation occurs, length of the separation, health of the family, disruptiveness of the incarceration, child's familiarity with the placement or new caregiver, strength of the parent-child relationship, number and result of previous separation experiences, nature of the parent's crime, length of the parent's sentence, availability of family or community support, and degree of stigma that the community associates with the incarceration. ${ }^{194}$

Yet as a whole, the disadvantage is significant even when the parent's involvement prior to incarceration was not high. ${ }^{195}$

The wounds of parental incarceration can cut extremely deep, as the evidence above has shown, and the proposal for incarceration insurance is by no means a panacea. At a minimum, however, incarceration insurance provides much-needed dollars to plug the loss of income from incapacitation of a parent's contributions from prison and from post-prison earnings reductions. By providing the child with an upfront state subsidy, the immediate effects of resource deprivation due to the exit of a parent to prison can be mitigated. In addition, incarceration insurance stabilizes the child's home conditions by lessening strains on their caregivers, thus alleviating another indirect cost of

192. Irwin Garfinkel, Sara S. McLanahan \& Philip K. Robins, Child Support and Child WellBeing: What Have We Learned?, in CHILD SUPPORT AND CHILD WELL-BEING 17-18 (Irwin Garfinkel, Sara S. McLanahan \& Philip K. Robins eds., 1994) (internal citations omitted). Though we may not know how precisely child support payments are allocated when they are paid to children, there is evidence to suggest that influxes to the child's custodial parent will increase his well-being. See also Nazli Baydar \& Jeanne Brooks-Gunn, The Dynamics of Child Support and Its Consequences for Children, in CHILD SUPPORT AND ChILD WELL-BEING, supra, at 258-59. For a deep study of the ways in which poor families headed by single mothers allocate scarce resources (including money from child support), see generally EDIN \& LEIN, supra note 72, at 22-23, 122. For an example of how poor children and their parents negotiate scarce material goods against the backdrop of consumer culture's influence, see generally CARL NighTINGALE, ON THE EDGE 147-50 (1993).

193. BERNSTEIN, supra note 3, at 2; Ross D. Parke \& K. Alison Clarke-Stewart, Effect of Parental Incarceration on Young Children, NAT'L. POL'Y CONF. (U.S. Dep't of Health and Human Servs. \& The Urban Inst., Wash. D.C.), Jan. 30-31, 2002, at 8.

194. Seymour, supra note 50 , at 4.

195. See, e.g., Geller et al., Beyond Absenteeism, supra note 137, at 72. 
incarceration on children. In this manner, incarceration insurance can alleviate the economic insecurity brought about by parental incarceration, and the marginal effect of this stopgap measure can be significant. Section $\mathrm{V}$ spells out some options for how much and in what form that plug should be-as well as what a reasonable payback scheme would look like--but the bottom line is that the severity of the resource gap indicates that some support is better than none at all.

\section{INCARCERATION INSURANCE}

For incarceration insurance to successfully reduce childhood disadvantage, the state must commit resources to fund the social insurance policy. This section offers three normative justifications for why the state has the obligation to provide social insurance in the form of parental incarceration insurance to children.

The state has long provided social insurance for children and adults, though there are gaps in its approach. ${ }^{196}$ The general justification for state-backed social insurance rests on the understanding that an individual faces the risk of economic insecurity at various points in the lifecycle. As Michael Graetz and Jerry Mashaw explain, "It is this vision of our common fates-the intuition that undergirds the common sentiment 'There, but for the grace of God, go I'-that provides the most important moral foundation for universalistic social insurance provision." 197 Social insurance serves as a bulwark against the risks associated with temporary, episodic, or permanent losses in labor income. ${ }^{198}$ In the United States and in peer countries, social insurance covers a class of risks that lead to income insecurity: illness and disability, old age, unemployment, death of a family breadwinner, and childhood poverty. ${ }^{199}$ Social insurance for children in particular has been conceptualized as a response to childhood as a life-cycle risk. It targets childhood as "a period when [people] are expectedindeed legally required-to be out of the workforce" 200 and vulnerable to economic insecurity not within their control.

$I$ argue that the state has an obligation to provide insurance against economic insecurity for children. Section A argues for the obligation from a theory about the moral status of children. Section B argues that the state has an obligation to provide incarceration insurance as a way of internalizing costs of mass incarceration that are currently pushed unfairly onto children generally

196. See GRAETZ \& MASHAW, supra note 23, at 65 ("Children, who are three times as likely as the elderly to be poor, have no federal entitlements program. They have no trust fund projections to catapult their income security needs onto the national agenda.").

197. See id. at 27.

198. Id.

199. $l d$. at 3 .

200. Id at 124 . 
and minority children in particular. Section $\mathrm{C}$ argues for an additional reason for the obligation on negative externality grounds, but focuses on the societal spillover effects of parental incarceration. ${ }^{201}$

\section{A. The Moral Status of Children}

Theorists of justice tend to presume that adults should be at least partially responsible for their own fates. We cannot assume the same for children, who are "not fully competent to determine and safeguard their own interests." 202 Children deserve social insurance against economic insecurity generally because they cannot choose their economic fates; they deserve incarceration insurance specifically because the economic insecurity exacerbated by parental incarceration makes these children especially unlucky.

Though he makes little mention of children specifically, Ronald Dworkin's analysis of luck and insurance presents a good framework for evaluating children's moral claims to incarceration insurance. Dworkin posits two forms of luck: option luck, "a matter of how deliberate and calculated gambles turn out," and brute luck, "how risks fall out that are not in that sense deliberate gambles." 203 Child poverty fits into the category of brute luck because "[c]hildren's actions are not implicated in their poverty." 204 Some formulate this as the risk of being unlucky enough to be "born into the wrong family." 205

Children are blameless in most regards, but particularly with respect to their own economic security. The actions of the incarcerated parent, on the other hand, are a fitting example of option luck from that parent's perspective. The incarcerated parent most likely made a series of deliberate decisions that

201. The three normative justifications provided in this section are not exhaustive. For example, some theorists and practitioners believe that the most important reason for public social insurance is preserving moral dignity for the vulnerable because "[e]conomic insecurity damages self-respect and the possibility of living in valued ways." Martha Holstein, A Normative Approach to Social Security: What Dignity Requires, in SOCIAL INSURANCE AND SOCIAL JUSTICE 233, 234 (Leah Rogne, Carroll L. Estes et. al., eds., 2009). The historical roots of Social Security as a project to secure "dignity in old age" present the most striking example of this commitment. An alternate possible argument for incarceration insurance is that it would be a thread in the fabric of a general social safety net, which must be constructed because the state has an obligation to eradicate child poverty because it erodes the capacity to actualize self-worth and dignity. Theories of a collective responsibility to support dignity are plentiful; they span the gauntlet from Peter Singer's consequentialist argument for moral commitments to alleviate suffering, see Peter Singer, Famine, Affluence and Morality, 1 PHIL \& PUB. AFF. 229-43 (1972), to the classic liberal argument espoused by John Rawls whereby dignity is a primary social good that those in the original position would demand. See JOHN RAWLS, A THEORY OF JUSTICE 440 (1971). Cast in this light, programs like Social Security are not mere utilitarian risk-reduction schemes but rather a moral collective effort by which "social citizens" fulfill their social obligations in an intergenerational compact. Martin Kohli, Retirement and the moral economy, in CrITICAL PERSPECTIVES ON AGING: THE POLITICAL AND MORAL ECONOMY OF GROWING OLD 273 (M. Minkler \& C. Estes eds., 1991); see also Holstein, supra, at 246.

202. GOLdSTEIN, FREUD \& SOLNIT, BEYOND BEST INTERESTS, supra note 147, at 3.

203. RONALD DWORKIN, SOVEREIGN VIRTUE 73 (2000).

204. GRAETZ \& MASHAW, supra note 23, at 119.

205. Id. at 119 (referencing Senator Daniel Patrick Moynihan's characterization). 
carried known risks of incarceration, and the event of going to prison is option luck odds playing out: as a losing hand. However, from the child's perspective, parental incarceration is classic brute luck. There is essentially nothing that the child can do to effect his fate vis-à-vis parental incarceration; the event is visited on him like an earthquake or a car accident. There is a parallel between being born with a serious handicap and being born to a parent who goes to prison: both are catastrophic, both are unpreventable by children, and neither hinges on mere differences in taste.

Dworkin explains that insurance can provide "a link between brute and option luck, because the decision to buy or reject catastrophe insurance is a calculated gamble." 206 He points out that there are instances in which people cannot buy insurance for conditions they are born with or conditions that they do not have funds or knowledge to insure against. ${ }^{207}$ Parental incarceration is an apt example. Although some conditions labeled as handicaps may be difficult to distinguish neatly from preferences and tastes, parental incarceration risk is not one of them. Instead, it is a circumstance that merits compensation from the public in order to "remedy one aspect of the resulting unfairness" 208 of brute luck.

A thought experiment is helpful to explain why children require state intervention in the context of both economic disadvantage generally, and in the case of parental incarceration in particular. Imagine a newborn endowed with the faculties of a rational decision maker standing with good information. That prescient infant would buy insurance against a number of potential adverse life events, including disability, illness, and unemployment. He would also insure against having parents who are unable to provide the level of economic security he needs. Specifically, he would want to insure against the loss of a caregiver or resource provider.

If the prescient infant knows some basic facts about his place in society: his race, class, geography, and family structure, and if he knows some of the startling facts already explicated in previous portions of this paper, that child would have a rational, informed basis on which to decide how much he should pay for poverty insurance and for incarceration insurance. For a child of white college professors, the premiums he would pay for both are probably very low because the risk of his parents going to prison is minimal. On the other hand, for an infant born to poor, young, unwed black parents in the Marcy Projects in Brooklyn who did not finish high school, it may behoove him to pay a great deal for the insurance.

Absurdity and reason intersect in this thought experiment. Everything about the decision making calculus for our prescient infant makes sense, but

206. DWORKIN, supra note 203 , at 74 .

207. Id. at 77 .

208. Id. at 81 . 
there are no prescient infants; even if there were, they do not have the funds to purchase the insurance. ${ }^{209}$ The agency problem is solved when a third party steps in to do what the prescient infant would have done. The thought experiment underscores the unique moral needs of the child, which is this proposal's normative focal point. That childhood-among other biological conditions in human life trajectories-are inevitable moments that require dependency on others is the theoretical basis for social insurance proposals. ${ }^{210}$

In a hypothetical world where social insurance comprehensively covers all child poverty risk, there would be no economical-security basis for incarceration insurance. In the real world, however, child poverty is a vastly underinsured risk. ${ }^{211}$ In the context of the Dworkinian insurance-risk analysis, the relationship between childhood economic disadvantage and the specific disadvantage of parental incarceration is one of degree and onset. As the evidence in Part II demonstrates, parental incarceration is a trigger for particularly severe economic insecurity. The proposal to insure against it identifies that trigger as a criterion for a heightened form of social insurance against child disadvantage.

Skeptics may argue that even if the state has an obligation towards child well-being, it might not want to intervene if another party also has an obligation and can better do the task. ${ }^{212}$ Thus, perhaps the families of children could purchase incarceration insurance. ${ }^{213}$ This is theoretically possible but, practically speaking, infeasible for four major reasons. First, the cost of incarceration insurance would be inversely correlated to the incomes of the parents such that those whose children are most at risk have parents who are least able to pay. Second, any pricing scheme would end up impermissibly racially tiered, since incarceration rates hew so strongly along racial lines. ${ }^{214}$

209. Indeed, as Gary Becker and Kevin Murphy observe, "a surprising number of state interventions mimic the agreements that would occur if children were capable of arranging for their care," and these interventions are net welfare enhancing. Gary S. Becker \& Kevin M. Murphy, The Family and the State, 31 J.L. \& ECON. 1 (1988).

210. See, e.g., Graetz \& MAShaw, supra note 23, at 119; Martha Albertson Fineman, The AUTONOMY MYTH 48 (2004).

211. See GRAETZ \& MASHAW, supra note 23, at 112.

212. But see FINEMAN, supra note 210 , at $47-49$ (arguing that "caretaking work creates a collective or social debt that each and that each and every member of society is obligated by this debt," and that society freeriders on the work of caretakers). Fineman argues that a "just state" should provide subsidies in the form of basic social goods, and also structure social and economic systems to "assume some fair share of the burdens of dependency." $I d$. at 285,287 . Fineman's framework requires a radical resorting of caretaking structures in society, but in the absence of this resorting, the current problem of a care and resource gap created by parental incarceration still needs to be solved.

213. One permutation is that incarceration insurance could work like flood insurance, whereby individuals can purchase protection from insurers, but FEMA provides backstop cost reduction in the form of the National Flood Insurance Program.

214. If the insurer were to price premiums based on the average person's risk of having a parent go to prison, the price might be low enough so that those at high risk of parental incarceration would buy in. The insurers may go broke as a result. But if insurers price based on the high-risk kids, the premiums would be astronomically high and many would be priced out of the market. 
Third, families may be reluctant to insure against incarceration for a whole host of reasons, including trust-however misplaced-in their loved ones and fear of stigma. Finally, the purchase of incarceration insurance would send problematic signals; law enforcement may have reason to believe that a family that buys incarceration insurance is likely to engage in law-breaking behavior.

Thus, the private actors implicated are especially unsuitable agents to enact an ex-ante insurance scheme. This market failure problem is not unique to incarceration, but is especially stark in this instance because it is the actions and identities of parents-who might otherwise be insurance purchasers-that precipitate the catastrophic event to be insured against. Thus, because a private insurance market cannot operate effectively to protect children against parental incarceration, and because the state does have an obligation to protect children of incarcerated parents, the state must provide social insurance to cover them.

For comparable risks to children like parental disability or parental death, there exist state-operated social insurance programs. The exit of a parent through death or disability confers some of the same negative income effects on children as parental incarceration. ${ }^{215}$ The U.S. government provides public social insurance against the risk of the death of a family breadwinner through Social Security survivor benefits. ${ }^{216}$ Both widowed spouses and survivor children get benefits from deceased workers. In $2010, \$ 105$ billion worth of payments were made from the Social Security survivor benefits program. ${ }^{217}$ Children of disabled parents also can receive support through Social Security disability benefits or Supplemental Income disability benefits. Just as parental disability is a brute luck event from the perspective of the child, so is parental incarceration. The rationale behind providing these social insurance programs for children suffering those risks addressed by SSDI and Survivor's Benefits should extend to a salient risk for today's children: parental incarceration.

\section{B. Rectifying Mass Incarceration's Harms to Children}

A second and independent normative justification for the government's obligation to provide incarceration insurance for children is on the grounds that children bear a disproportionate amount of the cost of the state's punitive incarceration policy. In identifying the state as a harbinger of parental

215. There are, of course, some differences even on the income deprivation dimension. Death-and sometimes disability - are permanent removals of parental income, so the cumulative impact of these exits are probably higher than most parental incarceration episodes (except life or death sentences). However, incarcerated parents also impose costs on their families while in prison, which dead parents do not. Finally, incarcerated parents have lower lifetime earning potential, while the families of deceased or permanently-disabled parents do not suffer parallel consequences.

216. See MARMOR, MASHAW \& PAKUTKA, supra note 22, at 101 .

217. See id. 
incarceration risk and ascribing responsibility to it, ${ }^{218}$ I argue that the state must redeem the negative externalities resulting from its deliberate enactment of a regime of mass incarceration.

\section{Government's Role in Exacerbating Parental Incarceration Risk}

In all societies, children lose out on resources and support due to unequal distribution not within their control. Parental incarceration is one of those drivers of unequal distribution. Though the argument for incarceration insurance applies to all children-in the United States or elsewhere, and regardless of whether the parent is incarcerated for insider trading or for drug trafficking - the U.S. government's role in increasing parental incarceration risk for children creates a particularly strong obligation for this state. In no other contemporary society is the magnitude of the problem so big, or its development so deliberate. Because the United States' mass incarceration regime $^{219}$ is the reason why parental incarceration risk is so high for children (especially poor black children), and because the cost of this regime has been unduly placed on these children, the state has an obligation to provide incarceration insurance.

This obligation rests on the uncontroversial premise that agents promulgating a social policy should internalize the costs of the policy. In this context, the state has not internalized the costs of mass incarceration; instead, the costs are borne by children of incarcerated parents, who of course had no role in enacting the policy. Indeed, these children are temporarily barred from effecting any changes in the policy in the future, since children cannot vote. Thus, the state's role-or at least its complicity - in creating outsized parental incarceration risk compounds on its obligation to the innocent bearers of that risk.

The claim that the state took deliberate action that increased the risk of parental incarceration is not up for serious dispute. Not only has the American state chosen incarceration as the solution to transgressions of the law, it has also elected to use a particularly aggressive and totalizing way of incarceration. This choice was not inevitable: prior to the 1970s, American criminal policy situated prisons as a "back-up institution, infrequently used," and the political campaigns of the 1970 s and 1980 s championing "law and order" triggered the

218. See Alfred Blumstein \& Allen J. Beck, Reentry As a Transient State Between Liberty and Recommitment, in PRISONER REENTRY AND CRIME IN AMERICA, supra note 114, at 50, 79 (concluding that growth in incarceration is not a consequence of growth in crime but rather policy decisions, as partly evinced by variations in state policies and accompanying incarceration rates).

219. See Natasha A. Frost \& Todd R. Clear, Understanding Mass Incarceration as a Grand Social Experiment, in SPECIAL ISSUE: NEW PERSPECTIVES ON CRIME AND CRIMINAL JUSTICE 159, 160-61 (Austin Sarat ed., 2009) ("[O]ur commitment to a policy of incarceration is now so entrenched that we have created the problem of mass incarceration."). 
move towards penal reality today. ${ }^{220}$ The shift occurred not as the result of a particular unconscious or unexamined decision but rather as a purposeful agenda, the crystallization of a continuous series of policies. ${ }^{221}$ Some contend that the policy is "best understood as a grand social experiment," whereby the "Punishment Imperative" pushed out all alternative responses to crime. ${ }^{222}$ It was "a major change in social policy enacted in order to gain certain utilitarian ends." 223

Virtually all evidence shows that the meteoric rise in prevalence of mass incarceration and parental incarceration risk ${ }^{224}$ was driven by the administration of penal law by the state. As Marc Mauer explains,

88 percent of the tripling of the national prison population from 1980

to 1996 is explained by changes in the imposition of punishment (51

percent a greater likelihood of incarceration upon conviction and 37

percent longer prison terms), while changes in crime rates explain only

12 percent of the rise. ${ }^{225}$

The United States's law enforcement policies on drug crimes has thus created what legal scholar Dorothy Roberts calls a "prisoner-generating machine."226 Although many scholars critique these policy changes from a number of fronts, ${ }^{227}$ I do not take up that project here. However, many policymakers do recognize the empirical reality that a system that intensively punishes drug crimes can be not only unfair, but also quite expensive. ${ }^{228}$ For example, U.S. Attorney General Eric Holder, in urging the U.S. Sentencing Commission to revise the Federal Sentencing Guidelines to reduce the average sentence for drug trafficking crimes, noted that such a change would reduce the

220. See ALEXANDER, supra note 28, at 46-53 (documenting the rhetoric and actions of Nixon and Reagan in galvanizing crackdowns on crime).

221. See $i d$. at $52-57$ (describing the continuous path of federal policies pursuant to the War on Drugs from the 1980 s to the Clinton era).

222. Frost \& Clear, supra note 219 , at 161 . They define grand social experiments by three characteristics: aimed at a "pressing social problem," creates "a coalescence of political will and public enthusiasm for a "new approach," and "gains momentum as . . widely accepted." Id. at 163 (emphasis removed). Other such experiments include the New Deal and the Great Society. Id. at 166-68.

223. Id. at 161 .

224. See supra Part II.A.

225. Marc Mauer, The Causes and Consequences of Prison Growth in the United States, in MASS IMPRISONMENT: SOCIAL CAUSES AND CONSEQUENCES 4, 6 (David Garland ed., 2001).

226. Dorothy E. Roberts, The Social and Moral Cost of Mass Incarceration in African American Communities, 56 STAN. L. REV. 1271, 1275 (2004).

227. There is near consensus amongst criminologists that "huge prison populations are a policy error." CLEAR, supra note 8, at 176-77 (citing David Garland, Loic Wacquant, James Austin, John Irwin, John DiJulio, and others scholars across methodologies).

228. Goffman also makes the point that aggressive stances to crime can generate more crime: "Thus, the great paradox of a highly punitive approach to crime control is that it winds up criminializing so much of daily life as to foster widespread illegality as people work to circumvent it. Intensive policing and the crime it intends to control becomes mutually reinforcing. The extent to which crime elicits harsh policing, or policing itself contributes to a climate of violence and illegality, becomes impossible to sort out." GOFFMAN, supra note 27, at 199-200. 
federal prison population by 6,550 inmates and "help rein in federal prison spending while focusing limited resources on the most serious threats to public safety.",229

The instant proposal, however, looks beyond just budget costs. Whatever benefits the state reaps from its criminal justice policy, ${ }^{230}$ it does so partly on the backs of poor children. This should make the obligation to pay these children back especially persuasive. One could also be agnostic as to whether there are actually social benefits from or a normative need for the mass incarceration boom, but posit that the state nevertheless must properly account for the fact that innocent children are bearing the costs of a failed policy initiative. ${ }^{231}$ Although the failures and successes of this grand social experiment are the subject of inquiry and debate, ${ }^{232}$ the question of whether society is in fact better off as a result of the mass incarceration regime is irrelevant to the question of whether the experiment imposes undue costs on certain parties. The havoc it wreaks on children is disproportionate and unfair.

In addition to putting more parents in prison and incapacitating them from contributing to their children's lives, the state also chose a regime that limits the ability of the formerly incarcerated parent to contribute after they are released. The formal barriers to employment, including shuttering access to education training and public housing, were all constructed in tandem with the mass incarceration strategy. ${ }^{233}$ Thus, the state not only is responsible for deliberately putting more parents in prison, but also for reducing their ability to contribute to the welfare of their children.

Incarceration insurance not only demands that the state redeem its history of free-riding on disadvantaged children. It also requires that in the future, the state must "put its money where its mouth is." Because the same entity that decides who should go to prison, for what, and for how long would be the entity that pays for the negative externalities of that policy, and it would also be the same entity that stands to recoup that cost from the incarcerated parent afterwards, finally the incentives can align. If the state would like to avoid

229. Attorney General Holder Urges Changes in Federal Sentencing Guidelines to Reserve Harshest Penalties for Most Serious Drug Traffickers, U.S. DEP'T. OF JUSTICE OFFICE OF PUB. AFF., Mar. 13, 2014, http://www.justice.gov/opa/pr/2014/March/14-ag-263.html.

230. For evidence that demonstrate that at least some reductions in crime rates can be attributed to the growth of incarceration, see WESTERN, supra note 43, at 185 (noting that the crime drop in the 1990s may be attributed to heighted incarceration, but that the effect is not particularly strong); William Spellman, What Recent Studies Do (and Don't) Tell Us about Imprisonment and Crime, 27 CRIME. \& JUST. 419 (2000); Don Stemen, Reconsidering Incarceration: New Directions for Reducing Crime, VERA INSTITUTE (2007), http://employees.oneonta.edu/ostertsf/Reconsideringlncarceration_

Veralnstitute.pdf.

231. For strong critiques of whether mass incarceration actually benefits social safety, see, for example, AlEXANDER, supra note 28; Clear, supra note 8; Frost \& Clear, supra note 219, at 177; Western, supra note 21.

232. See, e.g., Roberts, supra note 226; Pettit \& Western, supra note 42.

233. See ALEXANDER, supra note 28, at 56-57; Uggen, Wakefield \& Western, supra note 80 , at 237. 
paying too much, it can do one or both of two things: incarcerate fewer people, or provide more opportunities for ex-inmates to earn wages to pay back into the program. This places a burden on the state: it cannot wash its hands clean of the negative externalities of its penal policy. It is only a "new" burden in the sense that the state has ignored it in the past; it should have been borne by the state all along.

\section{The State's Obligation to Equality of Opportunity for Children}

The previous sub-section argued that the picture of who gets incarcerated in America demonstrates that the actions of a particular parent are only a partial factor in the creation of incarceration risk for children; the state is at least as complicit in creating and exacerbating parental incarceration risk. But beyond creating an across-the-board higher risk of parental incarceration for all children, the state also heightens the risk specifically for black and poor children. To review, a black child born in 1990 with a parent with low educational attainment has an over 50 percent chance of suffering the tragedy of paternal incarceration, compared to 7 percent for white children generally. ${ }^{234}$ The percent of black children suffering parental incarceration is ten times that of white children. ${ }^{235}$ The racial disparity is also growing. ${ }^{236}$

Calling on the state to rectify its "free-riding" on costs borne by children of incarcerated parents does not have to require accounting for how those external costs are racially distributed. However, that poor black children are the overwhelming victims of these unaccounted-for costs is salient for two reasons. First, this provides additional evidence that the state is culpable in creating incarceration risk. Second, because mass incarceration's effects are more severe for these children than for other children, the state has another independent reason to provide incarceration insurance: because it needs to provide equality of opportunity for children.

As Michelle Alexander argues, the penal regime in America can be characterized as the "new Jim Crow" because it is not merely the fallout of a racially neutral policy with racially disparate consequences, but rather the result of deliberate discrimination through penal policies that target marginalized groups. ${ }^{237}$ Alexander is not the first to raise the idea that mass imprisonment in America is not the residual outcome of an even-handed criminal administration regime. Loic Wacquant argued over a decade ago that the American prison system is a "judicial ghetto," and in conjunction with the neighborhood ghetto,

234. See Wildeman, supra note 6 , at 273.

235. See Wildeman \& Western, supra note 53 , at 162.

236. See Wildeman, supra note 6, at 271-80. Wildeman's research does show that not all of the disparity is due to state-controlled factors; other factors include disparities between the age growth of black versus white parents, and changes in marriage rates among blacks. $I d$.

237. See ALEXANDER, supra note 28 , at $182-83 ; 190-200$. 
falls into the category of "peculiar institutions" that also encompasses chattel slavery and Jim Crow; these systems aim to suppress, confine, and coerce the black population. ${ }^{238}$ Wacquant furthers observes that what is commonly referred to as mass incarceration is actually the "hyperincarceration of one particular category, lower-class African American men trapped in the crumbling ghetto," which leaves the rest of the masses "practically untouched" and the regime largely untouched by political dissent. ${ }^{239}$

Specific examples of racial disparity in the American criminal justice system are a dime a dozen. The sources of these discriminatory practices are myriad, but one is in police investigatory practices that yield racially skewed results. ${ }^{240}$ Heavily-publicized examples include the events in Ferguson, Missouri in August 2014 that is the subject of parallel FBI and Department of Justice civil rights investigations, ${ }^{241}$ and the New York Police Department's stop-and-frisk regime. ${ }^{242}$ Though the New York stop-and-frisk program has finally been found unconstitutional and reforms are underway, generally speaking racial profiling and racialized police tactics are far from eliminated. ${ }^{243}$ There are scant legal protections against racial profiling in vehicle-related searches and seizures in particular, as is made clear by the Supreme Court's ruling in Whren $v$. United States that pretextual searches are constitutional. ${ }^{244}$

238. Loic Wacquant, The New 'Peculiar Institution': On the Prison as Surrogate Ghetto, 4 THEORETICAL CRIMINOLOGY 377, 378, 383-85 (2000).

239. Loic Wacquant, Class, Race \& Hyperincarceration in Revanchist America, DAEDALUS, Summer 2010, at 78 .

240. See AlEXANDER, supra note 28, at 66-72. See also Tracey Maclin, Race and the Fourth Amendment, 51 VAND. L. REV. 331, 344-54 (1998) (providing empirical evidence to support the proposition that Fourth Amendment jurisprudence allows disproportionate racial consequences).

241. Sari Horwitz, Carol D. Leonnig \& Kimberly Kindy, Justice Dept. to Probe Ferguson Police Force, WASH. POST (Sep. 3, 2014), available at http://www.washingtonpost.com/world/nationalsecurity/justice-dept-to-probe-ferguson-police-force/2014/09/03/737dd928-33bc-1 le4-a 723-

fa3895a25d02_story.html; Mark Berman, FBI Opens Investigation Into Shooting of Michael Brown, WASH. POST (Aug. 11, 2014), available at http://www.washingtonpost.com/news/postnation/wp/2014/08/11/fbi-opens-investigation-into-shooting-of-michael-brown/.

242. See Floyd v. City of New York, No. 08 Civ. 1034(SAS), 2013 WL 4046209, at *562 (S.D.N.Y. Aug. 12, 2013), appeal dismissed, Sept. 25, 2013 ("[T]he City adopted a policy of indirect racial profiling by targeting racially defined groups for stops based on local crime suspect data. This has resulted in the disproportionate and discriminatory stopping of blacks and Hispanics in violation of the Equal Protection Clause."). The City has since agreed to settle the case on the terms outlined by Judge Scheindlin in her opinion, and settlement is pending approval by District Judge Analisa Torres. Benjamin Weiser \& Joseph Goldstein, Mayor Says New York City Will Settle Suits on Stop-and-Frisk Tactics, N.Y. TIMES (Jan. 30, 2014), available at http://www.nytimes.com/2014/01/31/nyregion/deblasio-stop-and-frisk.html. This settlement came after the Second Circuit Court of Appeals removed Judge Scheindlin from Floyd and its companion case Ligon, and remanded to a new Southern District of New York judge. ORDER, Ligon, et al. v. City of New York, et al.; Floyd, et al. v. City of New York, et al., 13-cv-3123; 13-cv-3008 (2d Cir. Oct. 13, 2013).

243. See, e.g., AMERICAN CIVIL LIBERTIES Union of ARIzONA, Driving While Black or BRown 6-7 (2008), available at http://www.acluaz.org/sites/default/files/documents/ DrivingWhileBlackorBrown.pdf.

244. Whren v. U.S., 517 U.S. 806, 813 (1996); see also United States v. Ibarra, 345 F.3d 711, 714 (9th Cir. 2003) (upholding an extraordinarily pretextual search and noting that "Whren foreclosed the 
This is accompanied by the Court's disinclination to intervene in cases alleging racial discriminatory policing. ${ }^{245}$ Thus, the entry point into the criminal justice system has a racial filter, and this entry-point inequality yields downstream inequalities.

The evidence presented in Part II shows that incarcerating a parent visits negative consequences on their children. Discriminatory laws, policing practices, and criminal administration together make black and poor children much more likely than white children to experience parental incarceration. Corroborating evidence includes new research showing that mass incarceration is linked to widening disparities in child welfare between blacks and whites. For example, had incarceration rates remained at 1973 levels, the decrease in likelihood of infant mortality would be about fifteen percent for black children and only about two percent for white children. ${ }^{246}$ In addition, mass incarceration since 1973 was the factor that accompanied a "65 percent increase in the already large black-white disparities in the risk of child homelessness."247

The Dworkinian analysis in the previous section already provides a clear rationale for why pursuing equality of opportunity for children is a moral obligation of the state. ${ }^{248}$ Because children cannot choose to be born into a certain race or class, life outcomes that are disproportionate on the basis of those arbitrary lines should be avoided. But because the inequality of outcomes in this particular instance are not merely driven by randomness, but rather by the actions of the state in policing certain races in more draconian ways, the state has an especially heightened burden to correct the inequity.

Through its policies and practices, the state pushes parents to exit. Its shove is more forceful for black parents than white parents, and the fall's impact has also become harder. The state has an obligation to all children; the obligation extends to all children of incarcerated parents because incarceration is a deprivation against which they need protection. The obligation is strengthened by the state's complicity in creating the risk of that deprivation. But the state also has a particularly strong obligation to the children of parents who are unjustly targeted by the criminal justice system. These are parents who, given an even-handed administration of criminal laws, would not have been incarcerated to begin with, or would have received lower sentences. These are

possibility that a search or seizure may be invalidated solely because of the subjective intentions of the officer").

245. See Reva B. Siegel, The Supreme Court 2012 Term, Foreword: Equality Divided, 127 HaRV. L. REV. $9,63-64$, n.310 (2013) (collecting cases on the Supreme Court's denial of certiorari in racial profiling cases where plaintiffs are seeking redress through both the Fourth Amendment and the Equal Protection Clause, even as Whren leaves open the possibility of courts forbidding race-selective practices under the Equal Protection Clause).

246. WAKEFIELD \& WILDEMAN, supra note 78, at 143.

247. Id. at 147.

248. See supra Part III.A. 
children who, given a state with a more equal criminal justice system, would not suffer such marked deprivations from parental incarceration.

For a host of reasons, it is functionally impractical to require that the state provide more favorable insurance for children of black parents versus white parents. However, providing incarceration insurance across the board alleviates the problem of equality of opportunity because parental incarceration risk is so much higher for black children. In other words, incarceration insurance will benefit more black children than white children, but this outcome is exactly right, because more black than white children suffer from heightened risk of parental incarceration in the first place.

However, the equality-creating characteristic of incarceration insurance should by no means be viewed as a justification for continuing a racialized penal regime. Rather, it should be a starting point for the state to take an honest look at its policies and its disparate treatment and effect on marginalized communities, and to acknowledge that the New Jim Crow regime is not only an injustice for those who get incarcerated, but also creates a society where children begin on unequal footings as a result of perniciously asymmetric state action towards their parents.

\section{Social Impact of Mass Parental Incarceration}

\section{Addressing Social Harms}

A separate, utilitarian perspective on parental incarceration is that the state has an obligation to internalize the cost of its mass incarceration scheme: the collective social negative externalities resulting from mass parental incarceration. Parental incarceration exacerbates childhood disadvantage, which in turn creates negative externalities for society. The state should correct those negative externalities through incarceration insurance because it has an interest in maximizing collective social welfare.

As demonstrated previously, parental incarceration reduces financial and quasi-financial support and is in itself a destabilizing force in children's socioemotional and physical well-being. Across numerous studies, children with incarcerated parents have been found to experience more negative life events, which cannot be expected to be contained within the family. ${ }^{249}$ Incarcerating parents creates "a set of second-order problems that furthers social detachment." 250 Various long-term negative effects on children include: "alcohol and substance abuse, behavior problems, attachment insecurity, cognitive delays, academic failure, truancy, criminal activity, and adult

249. See CLEAR, supra note 8 , at 117-18 (charting a summary of studies on the collateral consequences of incarceration on families, children, the economy, and communities).

250. BRAMAN, supra note 9 , at 221 . 
conviction and incarceration." 251 While some children adapt and cope with the trauma and disadvantage of parental incarceration, these net effects still manifest in demonstrated negative outcomes.

As children are exposed to severe hardships stemming from parental incarceration, the culmination of these factors results in a grave risk of perpetuating negative societal consequences. Consequences such as school performance declines, depression, aggression, and other problems resulting in lowered chances of life success ${ }^{252}$ have spillover effects. Growing up in economically depressed environments is a major risk factor for future criminal involvement. ${ }^{253}$ Some studies show that incarceration has self-perpetuating elements, including evidence that father absence and economic stress increase the risk of youths' criminal involvement. ${ }^{254}$ The connection between these bad outcomes and public safety is almost certain. "It requires a stretch of logic to think that concentrated incarceration... [is] a source of all of these problematic neighborhood dynamics without affecting crime."255 Todd Clear explains that incarceration creates social disorganization in neighborhoods by destabilizing their foundations and thus creates recursive negative effects:

$[\mathrm{H}]$ igh rates of incarceration can destabilize communities in ways that make them vulnerable to crime. The argument draws upon social disorganization theory, which has long held that in areas where residents are highly outwardly mobile, crime will flourish, because those locations will lack the stable infrastructure that is required as a foundation of informal social control. ${ }^{256}$

The utilitarian argument posits that these large, knock-on effects of parental incarceration merit state intervention. Providing children of incarcerated parents with economic resources to alleviate income insecurity lowers the economic stress and promotes the likelihood of better outcomes for these children. When society insures children against adverse outcomes, "the

251. Julie Poehlmann, Children of Incarcerated Mothers and Fathers, 24 WIS. J.L. GENDER \& SOC'Y 331, 336-37 (2009).

252. See ClEAR, supra note 8 , at 101-03 (outlining various findings of negative outcomes for children).

253. See $i d$. at 109 (reviewing literature supporting the link between economic depression and crime).

254. See Don Weatherburn \& Bronwyn Lind, Delinquent-Prone Communities (2001) (developing a thesis that economic stresses and poor parenting lead to crime); BRAMAN, supra note 9, at 90; Cynthia Harper \& Sara McLanahan, Father Absence and Youth Incarceration (Princeton Univ. Ctr. for Research on Child Well-being Working Paper No. 99-03, 1999) at 33. Given the voluminous record from decades of sociology research, is virtually indisputable that "high rates of incarceration destabilize families, increase rates of delinquency, increase rates of teenage births, foster alienation of youth from pro-social norms . . . and weaken labor markets." CLEAR, supra note 8, at 173.

255. CLEAR, supra note 8, at 173.

256. Todd Clear, The Problem with Addition by Subtraction: The Prison-Crime Relationship in Low-Income Communities, in INVISIBLE PUNISHMENT, supra note 67, at 182. 
insured is not just the poor child or the poor family with children, but also the society as a whole." ${ }^{257}$ Child poverty is a societal problem, as it is strongly associated with "low levels of educational attainment and a substantially increased likelihood of low productivity as an adult. Poor children are twice as likely as non-poor children to repeat a grade in school, to be suspended, or to drop out of high school." ${ }^{258}$ Because children with incarcerated parents are at greater risk of poverty, ${ }^{259}$ the state has a stake in minimizing social welfare losses stemming from this risk factor.

Childhood disadvantage conferred by mass parental exit through incarceration can be understood as the clustering of individual devastations, and these devastations have collective social consequences. Thus far, these social consequences have not been taken into consideration by the state, but they are a direct cost of the parental incarceration regime. Society has an obligation to address the costs of parental incarceration, as it is a salient driver of childhood disadvantage that inevitably turns into future social ills.

\section{Netting Out Costs}

The prevention of the harms above-even if partial-confers a utilitarian benefit on society in reducing future economic insecurity, crime, and other forms of adversity. However, the program of providing incarceration insurance also comes at a cost to society. A conservative estimate of a $\$ 500$ per year payment to the 2.6 million children of incarcerated parents nationwide would net to $\$ 1.3$ billion. If formerly incarcerated parents pay back half of that per year, the cost of the program, excluding administration outlays, is still substantial at $\$ 650$ million per year for the government.

The arguments in Parts A and B stem from moral status and equality-based normative commitments and stand independent of the budgetary cost. This section, however, analyzes whether the state's use of taxpayer dollars to internalize negative social externalities nets out in favor of paying for incarceration insurance.

One avenue toward answering this question is through the lens of children as public goods. ${ }^{260}$ As Gary Becker characterizes it, successful state provisions to children can be seen as "investments" in children, who eventually become future wage earners and taxpayers. Through this lens, instead of viewing the

257. NANCy Folbre, VAluing ChILdREN 179 (2010); Graetz \& MASHAW, supra note 23, at 120

258. GRAETZ \& MASHAW, supra note 23, at 120.

259. See supra Part II.C (providing empirical data demonstrating parental incarceration exacerbates poverty).

260. But see GRAETZ \& MASHAW, supra note 23, at 126. The authors caution against viewing children as future workers, but instead posit that there is a "special stake in preventing childhood poverty." Id. at 120 . They note that "[c]hildren are leading current lives, not just preparing for some future one." $/ d$. at 126. 
family as atomistic units, children are "becom[ing] increasingly public goods" and, correspondingly, "parenting becomes an increasingly public service.",261 Indeed, scholars have extended this to hold the view that "[t]hose who benefit from children's future income do so partly at the expense of present-day parents" and conclude that parenting should be viewed as a public good as well. ${ }^{262}$ In this conception, incarceration insurance is not a burden on the public but an investment that plugs into the gap where the public service investment of parents have failed. Investing in incarceration insurance can confer social benefits by preventing particular harms on children's well-being. Since parental incarceration poses a particular threat to the likelihood that children of incarcerated parents will not reach a maximum level of social productivity and income-earning, investments in counteracting that threat should be evaluated in terms of future returns.

A salient example of this argument is compulsory public education, which is of course funded by the state. An upfront investment in children's welfare also confers long-term benefits on society. As long as the present value of the future contribution of children on a marginal basis exceeds the cost of insuring them, the payoff is net positive for society. ${ }^{263}$ Cast in this light, social policies that involve wealth transfers to children are not just that; they are better characterized as investments in these children's future well-being and wealthcreation potential, which in turn bolsters societal welfare. ${ }^{264}$

Furthermore, the damage to children's well-being through parental incarceration can wreak havoc in the "returns" on the investment that the state makes in other child-welfare programs, such as education and health. ${ }^{265}$ Thus, incarceration insurance can also be thought of as a second-order "metainsurance" of the effectiveness of general social insurance for children. The future returns of this investment are difficult to calculate, particularly because its results will likely depend on how the insurance program is implemented. However, in thinking through the costs and benefits to society of taking on this incarceration risk program, the future payoff value of the program is important to keep in mind.

261. FOLBRE, supra note 257 , at 86.

262. Id. at 87 . See also FINEMAN, supra note 210 , at $47-48$ (though Fineman's argument that society owes a collective social debt to caretakers does not hinge on viewing children as social goods).

263. Gary BeCKer, A TREaTISE ON THE FAMILY 14 (1993).

264. For a preliminary discussion of potential ways to calculate the return on investment in early childhood education and child health initiatives, see FOLBRE, supra note 257, at 180-81.

265. This does not require holding the view that children are social goods, but merely that social investments should be allocated efficiently. 


\section{DEFINING PARENTAL OBLIGATION}

\section{A. Why Parents Must Pay}

The state has an obligation to provide for child welfare in response to parental incarceration, but the proposal does not require that the state go it alone. The proposal requires the state to provide upfront social insurance to children of incarcerated parents, and also requires the incarcerated parent to contribute. By ushering the state to step in, but also by linking the parental obligation to pay for incarceration insurance with the notion of parental responsibility, this proposal aims to resolve the tension between the goal of bolstering economic security for children and the "widely held and sensible beliefs concerning parental responsibility." 266

First, the proposal requires inmate parents to eventually contribute because incarceration does not erase parental duty. Though incarceration incapacitates the parent from fulfilling some of his parental duties, the parent still has obligations to his children. One reason is that incarceration does not-and should not-terminate parental rights. Insofar as the parent has an ongoing future stake in his child's life, he must also uphold the responsibilities that come along with that stake. As Lawrence Mead states in his argument for work-based entitlements,

The idea is that parents are responsible in some sense for themselves and the families they have brought into being ... While individuals make claims for sustenance through politics and their own labors, they must also contribute to a reservoir of resources, both economic and moral, shared by all the citizens. ${ }^{267}$

The instant proposal seeks to make those responsibilities reasonable to fulfill. However, the parent should not be able to abdicate responsibility while maintaining parental status.

In addition, the parent's choice to commit crime makes him complicit in the creation of disadvantage to his child. Though the distribution of criminal sanctions can be uneven, the criminally-involved parents are not free of parental obligation generally, or of the embedded obligation to reverse the harms resulting from incarceration to the children. This comports with what Dworkin calls option-luck, even if for some parents the menu of options is more restricted than for others. Many similarly situated parents choose not to commit crimes, and their actions provide the ultimate "insurance" for their

266. GRAETZ \& MASHAW, supra note 23 , at 10

267. LAWRENCE MEAD, BEYOND ENTITLEMENT 244, 246 (1986). 
children against the harms of parental incarceration. ${ }^{268}$ Regardless of what factors motivate parents to commit crimes, incarcerated parents know that their actions might incur consequences for their children. It seems unjust and strange, therefore, to absolve these individuals of any responsibility for creating this risk. Instead, the parent should internalize some of the costs of incarceration that are currently borne by his children.

Another important rationale for mandating contribution from the inmate parent is equity. Insofar as the non-incarcerated parent or relative retains responsibility for providing for the children, it is unfair to release incarcerated parents from contributing. The remaining parents must "face the dual challenges of working in the paid labor market and being the primary parent and child caretaker" as well as the "extremely limited availability of public support." 269 If parents who do not engage in criminal activity are expected to make large outlays to providing for child well-being, it is unquestionably inequitable to release criminally involved parents from responsibility. ${ }^{270}$

\section{B. Impact on Inmates}

Many incarcerated parents are already poor and face tremendous disadvantages. ${ }^{271}$ Despite the fact that they maintain the obligation to provide for their children, a proposal to impose further burdens on incarcerated inmates should still be scrutinized from the perspective of impact on the inmate. The following sections evaluate what form this program would take in the context of the inmate parent's position.

\section{A Change to the Current Child Support Regime}

In most states, child support accrues against incarcerated parents even though they cannot possibly pay while in prison. The instant proposal replaces the child support orders for incarcerated parents, thus making little to no

268. For examples of the life-paths of members of high-crime communities who do not pursue criminal activity, see GOFFMAN, supra note 27, at 163-85, 193-94.

269. Cancian, Meyer \& Han, supra note 190, at 143.

270. See infra Part IV.C (discussing the non-incarcerated parent). From an empirical standpoint, it is not clear that parents who exit from their parental obligations through prison or otherwise end up worse off than their children. In the child support context, "there is some evidence that on average, nonresident fathers are better off than resident mothers and their children." Id. (citing data that 15 to $25 \%$ of nonresident fathers are below poverty while $27 \%$ to $46 \%$ of resident mothers fall below the poverty line, but noting that there may be selection bias in the sample). Of course, incarceration is a brutal experience, so there may of course be differences between incarcerated parents' and noncustodial parents' socioeconomic outcomes.

271. See Western \& McLanahan, supra note 64, at 312 ("Incarceration is a watershed event that can disrupt key life course transitions setting in motion a downward spiral of accumulating disadvantage."); BRAMAN, supra note 9, at 154 ("Many inner-city families not only experience incarceration because they are poor, but they are atso poor because they experience incarceration."). 
difference in some inmates' accrual of obligations. ${ }^{272}$ Thus, for at least some inmate parents, the instant proposal is a net positive in that their children receive actual wealth transfer today, but the obligation against the parent is not substantively different than before.

Making incarcerated parents accrue child support arrears without providing anything to the children is ineffective in bolstering child well-being. ${ }^{273}$ It is estimated that "[f]athers typically enter prison with $\$ 10,000$ child support debt and leave owing $\$ 20,000$ or more." 274 Though in some states parents can reduce their orders while in prison, few know about the options, and even fewer use them successfully. ${ }^{275}$ These parents accrue arrears that are levied against them when they get out, but their children receive no benefits. As one advocacy organization put it:

When an incarcerated parent has no assets, setting child support orders at pre-incarceration levels will not tangibly support the child. All this will do is create arrears that cannot be collected. This has negative consequences for the noncustodial parent and the State . . Ultimately, these child support debts are not in the best interest of the child. ${ }^{276}$

The instant proposal replaces the ineffective child support obligation for the incarcerated parent, instead providing their children with usable resources during the duration of the parent's prison term. When combined with reasonable and thoughtful reentry programs as well as parenting resources, this program should make it easier, not harder, for inmates to provide for their children relative to the status quo.

\section{Countering Parental Alienation}

A second way in which incarceration insurance can impact the experience of prison for the incarcerated parent is that the payments provide a structural

272. Whether the financial burden of this program is similar to that of child support depends on particular program design, implementation, and the circumstances of the individual parent.

273. See Office of Child Support Enforcement, Incarceration, Reentry and Child Support Issues: National and State Research Overview, U.S. Dep't. of Health \& Hum. Serv. (2006) http://www.acf.hhs.gov/sites/default/files/programs/css/incarceration_report.pdf; Esther Griswold \& Jessica Pearson, Twelve Reasons for Collaboration Between Departments of Correction and Child Support Enforcement Agencies, CORRECTIONS TODAY (June 2003).

274. VICKI TURETSKY, STAYING IN JOBS AND OUT OF THE UNDERGROUND: CHILD SUPPORT POLICIES THAT ENCOURAGE LEGITIMATE WORK 1 (2007).

275. Many states do not allow child support order modification on the basis of incarceration because it is considered voluntary unemployment. For a full analysis of state approaches to reductions based on incarceration status, see Jessica Pearson, Building Debt While Doing Time: Child Support and Incarceration, 43 JUDGE's J. 4 (2004).

276. Brief for The Center on Fathers, Families \& Public Policy and The Wisconsin Council on Children \& Families as Amici Curiae, at 6, In re the Marriage of Toni L. Rottscheit v. Terry L. Dumler, No. 01-2213 (Wisc. June 25, 2003). 
link between the incarcerated parent and his children that can combat parental distancing. Disruptions in parents' life can have profound effects for their relationships with their children, and prison is no different. As Edin and Nelson note in their ethnography of inner-city poor fathers, few describe children as "millstones" but most see them as "life preservers, saviors, redeemers."277 Yet incarceration stakes a wedge between the ideal of parenting and reality. It not only makes it difficult for parents to provide for their children, but also alters their conceptions of parenthood. ${ }^{278}$

Both because of the totalizing power of the prison and because of confrontation with parental failure, prisoner parents often experience an acute displacement and distortion of their fatherhood identities and shirk from continuing or establishing parental ties. ${ }^{279}$ Ethnographic accounts have demonstrated that for many parents, the displacement and detachment triggered by incarceration prevent them from engaging in parenting roles after their release from prison. ${ }^{280}$ Incarceration insurance may alleviate some of these effects, first by reassuring incarcerated parents that their children are being provided for, and second by linking them to the welfare of their children through the deferred payment obligation.

Many parents in prison wish that they could be providing for their children and worry that their children are suffering from the loss of support. ${ }^{281}$ Anne Nurse's 2002 study of incarcerated young black fathers found that these meneven though their contributions to the welfare of their children prior to confinement was small-held visions of the "good father" as someone who "provides guidance, love and financial support to his children.",282

277. EDIN AND NELSON, supra note 83 , at 58 . The researchers note that few complaints about child support surfaced, and "the strength of the sentiment behind these fathers' words makes them all the more remarkable."

278. EDIN AND NELSON, supra note 83, at 173.

279. See ARDITTI, supra note 79; NURSE, supra note 16; BRAMAN, supra note 9.

280. See ARDITTI, supra note 79.

281. Limitations on families' abilities to visit inmate parents can exacerbate this issue. Many inmates go to prisons far away from their families, making visits nearly impossible. For example, female prisoners are often concentrated in one prison, and are geographically isolated from their home cities. Federal prison are often hundreds of miles from the communities where the prisoners' families live. Though there have been efforts to reform prison visitation, some of these reforms have met setbacks. For a recent review of visitation policies across the U.S., see Chesa Boudin, Trevor Stutz \& Aaron Littman, Prison Visitation Policies: A Fifty State Survey, Y.L. \& POL'Y. REV. (forthcoming 2014) http://www.law.yale.edu/documents/pdf/Liman/Prison_Visitation_Policies_A_Fifty_State_Survey.pdf. One of the ironic setbacks to visitation reform comes in the form of replacing physical visit access with "Skype visits," which are fundamentally different from in-person visits and could be inaccessible to many families without ready access to computers and internet networks. See Robert McCoppin, Video visits at llinois jails praised as efficient, criticized as impersonal, CHI. TRIBUNE (Jan. 12, 2014) http://articles.chicagotribune.com/2014-01-12/news/ct-jail-video-visits-met-20140112_1_inmates-andvisitors-video-visitation-john-howard-association.

282. NURSE, supra note 16, at 73. But see Monika J. U. Myers, A Big Brother: New Findings on How Low-Income Fathers Define Responsible Fatherhood, 34 J. FAM. \& ECON. ISSUES 253 (2013) (contending that other accounts of fatherhood might overemphasize financial contribution in what fathers think of as hallmark fatherhood duties). 
Inmates sometimes express deep regret about not being able to provide for their children, and that regret can transform into detachment, which wreaks even more havoc on any fragile relationships these parents might have with their children. ${ }^{283}$ As one inmate parent put it, "[I regret] not being a good father while in prison. I'm not really helping at all."284

There are two mechanisms by which parental detachment can take place. First, parents may face despondency when they learn of financial difficulties that their families face in their absence. ${ }^{285}$ "Financial difficulties faced by their families figure largely in the concern of many of these men since a majority of them contributed in some fashion to the finances of their families prior to incarceration."286 There are numerous ethnographic accounts of inmates lamenting the inability to provide for their families emotionally or otherwise. ${ }^{287}$ In interviews with 181 inmate parents in England, researchers found that these parents often used the vocabulary of defeat when describing how they felt about their incarceration's impact on their children: 15 percent said "gutted," 20 percent said "helpless", and 8 percent said "frustrated." 288 In a different study, an inmate mother noted this incapacitation as a reason for detachment: "It's so hard to write my kids. There's nothing to write but bad things." 289 Tripp's study found evidence of parental detachment as a result of helplessness, as "participants spoke of fatherhood in relation to their ability to purchase or provide financially for their children." Nine of the twelve African-American parents volunteered their inability to provide financial support as a major problem and many discussed at length their families' financial woes as result of or in concurrence with their imprisonment. ${ }^{290}$

A second and more nuanced mechanism by which fathers in particular may engage in distancing is that a major element of their fatherhood identity has been stripped away and replaced by an inmate identity. ${ }^{291}$ Fathers in prison often base "elements of their father identity on their ability to provide financially for their children or on their ability to purchase gifts for their

283. See Kennedy, supra note 14, at 94; Brad Tripp, Incarcerated African American Fathers: Exploring Changes in Family Relationships and the Father Identity, in IMPACTS OF INCARCERATION ON THE AFRICAN-AMERICAN FAMILY, supra note 105, at 17, 25-27 (chronicling similar sentiments in other inmates).

284. ARDITTI, supra note 79 , at 77.

285. See Tripp, supra note 283 , at 28 .

286. Miller, supra note 105 , at 5 .

287. See BRAMAN, supra note 9, at 110-11, 124-25, 141, 146; Tripp, supra note 283, at 25-28.

288. GWYNeTH Boswell \& PETER Wedge, Imprisoned Fathers AND THEIR Children 39 (2002).

289. Lynn Sametz, Children of Incarcerated Women, 25 SOC. WORK 298, 299 (1980).

290. Tripp, supra note 283 , at 28.

291. Some scholars and advocates have also critiqued the "deficit model" of adolescent parenthood, arguing that it sets up an expectation ex ante that excludes young fathers "from involvement in parenting fromt he start." J. Lyn Rhoden \& Bryan E. Robinson, Teen Dads: A Generative Fathering Perspective Versus the Deficit Myth, in GENERATIVE FATHERING: BEYOND DEFICIT PERSPECTIVES 105, 108 (Alan J. Hawkins \& David C. Dollahite eds., 1997). 
children." ${ }^{292}$ But when they cannot do so, that pre-inmate identity is slowly eroded and replaced with an identity shaped by their new everyday reality. Sociologists document the effect as "prisonization,"293 turning on the loss of agency and perspective while in confinement. ${ }^{294}$ This prison identity is an involuntary alteration. ${ }^{295}$ The loss of "self worth and competence that comes with parenting" accompanies a gradual shift from the fatherhood identity to the prisoner identity. ${ }^{296}$

The detachment exhibits itself in downplaying parental responsibilities, and is a particularly "troubling facet of incarceration" because it isolates prisoners "from an important source of support during the incarceration process," as it creates "minimization of the father role in these inmates' sense of themselves" and can lead to degradation that "may decrease these men's level of motivation to act as fathers after imprisonment." 297 This may exacerbate the already fraught relationship between the inmate father and the child's mother. The Fragile Families data show that fathers released from prison are " $50 \%$ more likely to have no relationship with their baby's mother a year after the birth" versus never-incarcerated men. ${ }^{298}$

Despite the evidence of detachment, there are also plenty of signs that men in prison are still committed to the idea of parenting. ${ }^{299}$ Some parents try to do everything they can while in prison, such as pushing for visits and writing cards and letters. In describing their fatherhood roles, inmates often used an "action orientation," describing specific performances like gift-giving on holidays. ${ }^{300}$ Thus, insofar as parenting actions are possible, there is some room for maintaining parenting identity. Indeed, ethnographers find that fatherhood 'identities sometimes lie dormant during the prison term instead of disappearing entirely. ${ }^{301}$

Of course, assuring incarceration insurance payments to children will not wholly counteract the effects of helplessness and of "prisonization." The power

292. Tripp, supra note 283 , at 25.

293. See C. Newton, Gender Theory and Prison Sociology: Using Theories of Masculinities to Interpret the Sociology of Prisons for Men, 33 HOWARD J. 193 (1994).

294. See ARDITTI, supra note 79, at 36.

295. Id. at 76.

296. Id. at 35. Arditti furthers, "[P]risonization involves the individual's inculcation of the prison subculture so much so that preprison identities 'fade' and the prison identity of 'inmate' ascends." $I d$. at 74 (internal citations omitted). See also Wm. Justin Dyer, Prison, Fathers and Identity: A Theory of How Incarceration Affects Men's Paternal Identity, 3 FATHERING 201, 202 (2005).

297. Tripp, supra note 283, at 28-29.

298. Western \& McLanahan, supra note 64, at 318-19.

299. There is also evidence that young fathers are particularly likely to exhibit detachment, whereas older parents are more likely to repair severed bonds or maintain relationships. See Edin, Nelson \& Paranal, supra note 90.

300. Id. at 25-26.

301. See ARDITTI, supra note 79. 
of the prison as a totalizing institution is great. ${ }^{302}$ However, the payments can make a difference in combating parental distancing, hence contributing to more contact while the parent is in prison and more of an impetus to continue parenting when released. That the payment is linked to the specific parent is critical because it creates a way for the incarcerated parent to feel that he is providing for his child. This is important because it drives a wedge-even if it is a small one-against the totalizing perceptive shift towards prisonization by maintaining a semblance of the inmate's sense of the self as a parent. ${ }^{303}$ While it is possible that some inmate parents may resent the mandatory repayment scheme, the fact that their children received tangible benefits during their incarceration may inspire some to believe that their incarceration was not all bad for their children. And to the extent that the incarcerated parent is expected to--and believes that he may-eventually pay back the costs, the incarcerated parent may be induced to feel like he has a stake in the welfare of his child. This stakeholder mentality might buttress the foundational parental identity that would spur support when the parent emerges from prison. ${ }^{304}$ This is important both in itself and also has recursive effects, as male parolees who have family networks and who return to living with their children and partners are less likely to reoffend. ${ }^{305}$

\section{Impact on the Non-Incarcerated Parent}

Incarceration insurance affects not only children and their incarcerated parents, but also the non-incarcerated parent or caretaker. Amongst young black men without high school diplomas, "more become incarcerated than either go on to attend college or hold a job." 306 They leave behind a significant population of their children and their children's caretakers-usually mothers ${ }^{307}$ and grandmothers. These caretakers bear the responsibility of caring for 130.

302. See generally ERVING GOFFMAN, ASYlums 1-125 (1966). See also ClEMMER, supra note

303. See Kennedy, supra note 14 , at $94-95$ (noting that “maintain[ing] incarcerated parents' selfperception as parents ... . can benefit both the incarcerated parent and his or her children ... . [by] foster[ing] childhood development and serve as a rehabilitation tool for parents.").

304. For example, Edin and Nelson conclude their detailed new ethnography of inner city poor fathers by suggesting that broad policies that promote "ongoing involvement" from poor fathers could focus them towards their children's well-being, including "stav[ing] off additional childbearing with new partners and leav[ing] fewer children on the father-go-around." EDIN \& NELSON, supra note 83, at 228.

305. ARDITTI, supra note 79 , at 90.

306. Lani Guinier \& Gerald Torres, The Miner's Canary: Enlisting Race, Resisting POWER, TRANSFORMING DemOCRACy 260 (2003).

307. See, e.g. Donald Braman, Families and Incarceration, in INVISIBLE PUNISHMENT, supra note 104 , at 117,128 (noting that because in certain neighborhoods, because so many men are in prison, " $t]$ he fact that men and women both perceive a significant shortage of eligible men shapes the way they approach relationships in troubling ways"). 
children without support while the other parent is incarcerated. Incarceration insurance will have a large impact on them.

I have already described the ways in which adult family members of the incarcerated-in particular the partners and mothers of incarcerated fathersbear outsized burdens in the wake of their imprisonment. Support to these families will alleviate some of the burdens, primarily by enlarging the meager pools of resources that the family must share.

Incarcerated individuals tend to be poor. ${ }^{308}$ Their families do worse economically as a result of their departure. ${ }^{309}$ The support that incarceration insurance can bring to these families-and especially to the non-incarcerated parent who is responsible for taking care of the child-can be dramatic. Accounts of poor single mothers' resource deprivation and daily dilemmas suggest that a subset of these single mothers-those who lose a partner to prison - are equally in need of support. Edin and Lein's ethnographic research revealed that poor single mothers lived "significantly below what most Americans would think an adequate standard.",310 They found that these families "regularly went without items that virtually every American would consider necessities" 311 such as housing, medical care, food, and winter clothing. ${ }^{312}$ In their exploration of how these single mothers "make ends meet" with welfare and low-income jobs, they found that for many, "child support was the single most important factor allowing them to work at a low-wage job." ${ }^{, 313}$ Another common concern was safe and adequate childcare, the lack of which often prevented single mothers from earning an income. ${ }^{314}$ Since inmate parents cannot meaningfully contribute child support or childcare, a corollary economic support mechanism needs to be in place to support these families. ${ }^{315}$

One might ask whether the non-incarcerated parent might also be considered complicit in incarceration risk-creation. The short answer to this question is no. There are structural problems with assigning responsibility to the non-incarcerated parent, one of which is that it is hard to predict which potential mates are prison-bound and which are not. While some individuals may have some idea of the ex ante risk that the other parent of their children has certain propensities for criminal behavior, the obligation to prevent this outcome is too attenuated, especially if these individuals have children while

308. See Pettit \& Western, supra note 42.

309. See supra Parts II.B \& II.C.

310. EDIN \& LEIN, supra note 72 , at 47.

311. Id.

312. Id. at $48-56$.

313. Id at 122 .

314. Id. at 133-35.

315. Part II.B.2 describes the many economic stressors associated with a spouse or partner going to prison. However, there are also accompanying socioemotional stressors that come from raising a family while one's partner is in prison. While incarceration insurance cannot directly address noneconomic concerns, alleviating the pressure of poverty will likely diminish the acuteness of socioemotional stressors on single parents as they raise children in the shadow of a partner's incarceration. 
they are themselves young, or if the criminal behavior in their partners does not manifest until after the child is born. But most importantly, it is likely that this parent is already bearing much of the uncaptured costs of child-rearing while the other parent is in prison, and even a robust incarceration insurance program would only partially make up for that additional burden.

\section{IMPLEMENTATION OPTIONS}

So far, we have explored the theoretical justifications underlying the proposal for incarceration insurance. The contours of the proposal's programmatic design, however, have not yet been discussed. This Part aims to define those contours in three sections. Section A refocuses the theoretical discussion towards the schematic of social insurance design and explains why the concern for the well-being of children of incarcerated parents should translate to this particular program for incarceration insurance. Section B explains why this specific scheme is the only one that adequately addresses the problem of collateral consequences on children due to parental incarceration. Section C maps out a matrix of programmatic options for implementation, including questions such as how the payments should be made, whether it should count against other public benefits, how much the incarcerated parent should pay, what programs should be available to encourage payment, and what enforcement mechanisms there should be for non-payers.

\section{A. Incarceration Insurance as Social Insurance}

I call my proposal "incarceration insurance," but note that it is both technically and substantially distinct from the traditional and commonlyunderstood notion of private insurance. Insurance typically involves a party paying an ex ante fee in return for compensation in case of a specified event. My proposal does not require the insured party to pay ex ante. There are two reasons for this difference. First, the degree to which the government controls the level of incarceration risk is higher than for many other insured risks, such as risk of disease or auto accidents. Second, the insured party in this situation has no control over the likelihood of the catastrophic event, and also cannot pay for it. The "fee" paid to the government as insurer is ex post, and thus at first glance, the proposal looks like a loan from the government to the incarcerated parent. But the goal of the program is not to issue loans, but rather to share the burden of the "fee" between the two responsible parties. ${ }^{316}$ The program's

316. One implementation option, discussed in Part V.C.3, is to charge the parent the would-be average premium for the whole program, versus the premium for the pool of those at high risk for incarceration. 
ultimate goals are the same ones that drive many other social insurance programs: providing protection against risks of adverse life events.

That programs labeled as social insurance do not hew to traditional notions of ex ante insurance premiums for later coverage is not new or surprising. ${ }^{317}$ In the realm of governmental social insurance, the link between an individual party beneficiary and the payment of an ex ante fee for protection is not crucial. For example, unemployment insurance is financed through employer taxes, and the unemployed individual collects the claim from the government. Thus, the employer never tailors the "fee" it pays to any particular employee, instead factoring in the cost of the program within its projections of the cost of hiring. $^{318}$ The unemployed person is paid out of a funding pool. We nevertheless define the program as a social insurance program because its intention is to insure people against the risk of losing their jobs.

Similarly, I call this program "incarceration insurance" because the goal of the program is to insure against a specified risk. The risk is viewed from the perspective of the child. The proposal separates the payer of insurance from the beneficiary of the insurance; this separation is based on the obligations theories discussed in Part III. Put simply, the obligation to pay does not rest on the children because they are not involved in risk creation. Rather, two constituencies - the state and the parent-have obligations to protect children from risk bear the burden, and the proposal institutes a cost-sharing mechanism from them both. Incarcerated parents eventually pay the government "back" to sustain the funding for the program, unlike pure entitlement programs that do not require any payment from beneficiaries or their families. As long as the mechanisms for delivering the insurance are effective and justified, the fact that they may not look like traditional insurance is irrelevant.

\section{B. The Policy Landscape}

This proposal is the first to link the problem of mass incarceration's collateral consequences on children to a social insurance program for those children. Other policy proposals, while recognizing a state obligation towards child welfare generally, have aimed to ameliorate childhood disadvantage from other angles without addressing the source of the problem directly. As I indicated in Part 1 , existing, conventional mechanisms, such as TANF and Social Security, do not adequately cover the disadvantage conferred onto children by their parents' incarceration. Even measures targeted at children

317. For a discussion on the distinction between private insurance and social insurance, see GRAETZ \& MASHAW, supra note 23 , at 26-28, 42-43.

318. States do usually require employers who lay off more workers to pay a higher unemployment insurance payroll tax, but this is still not directed at any particular worker. See MARMOR, MASHAW \& PAKUTKA, supra note 22, at 140. 
specifically, such as child-only TANF, do not actually protect against the specific risk of parental incarceration. In order to receive child-only TANF, the recipient must be living with caretakers who do not otherwise qualify for TANF. ${ }^{319}$ At most, it is a recourse for the child whose two parents are both unable to provide for her through TANF or otherwise. If we imagine a child whose father is incarcerated and whose mother is her caretaker but has lost TANF benefits, Child-only TANF is a stopgap for the mother's income contribution, but does not directly address the lost income from the incarcerated parent.

When we look to the universe of proposed solutions, even the innovative child-welfare plans are not sufficient to address harm specifically accruing to children of incarcerated children. An example of a pioneering policy proposal for children is Irwin Garfinkel's child support assurance system (CSAS), which would guarantee a minimum child support payment funded by the government. While the expectation is that the noncustodial parent would provide a standard rate of child support, the government would make up for the difference if the parent does not pay. ${ }^{320}$ This proposal is a more expansive view of the insurance problem for parental exit, but in the context of parental incarceration, there are two problems. First, many children with incarcerated parents do not have established child support orders and thus will not be covered by this program. Second, CSAS does not require payment from the noncustodial parent, which means there is a risk is that the compensation provided is over-inclusive and thus displaces parent-to-child transfers for those parents who can, but don't, pay full child support if they know the government will make up the gap. The program may also be too expansive for strained budget realities, and may create incentives for fraud - or at least perceived potential for fraud. While Garfinkel makes excellent arguments for why CSAS is more effective towards alleviating childhood inequality than child support enforcement in the status quo, and points out that CSAS in fact may be cost-neutral in the long run, the instant proposal pinpoints the one form of parental exit covered under the umbrella of CSAS that is most critical for government backstop.

Other child welfare ideas, such as Anne Alstott's proposal for caretaker resource accounts ${ }^{321}$ and Michael Graetz and Jerry Mashaw's proposals ${ }^{322}$ for wage supplements, childcare and housing subsidies, and increased survivorship benefits, are beneficial for children and their primary caretakers. But once again, they cannot account for the losses of support that arise specifically from parental incarceration. Alstott and Bruce Ackerman's stakeholder society

319. Olivia Golden \& Amelia Hawkins, U.S. Dep'T of Health \& Hum. Servis. TANF ChildONLY CASES (Jan. 2012), http://www.acf.hhs.gov/sites/default/files/opre/child_only.pdf.

320. See GARFINKEL, supra note 24 , at 8 . This program was implemented as a pilot program in Wisconsin and, to a limited extent, in certain counties in New York State.

321. See AlSTOTT, supra note 1, at 73-137.

322. See GRAETZ \& MASHAW, supra note 23. 
proposal $^{323}$ aims to resolve much of the equality-of-opportunity problem that motivates the need for social insurance, but by the time individuals reach the age to receive their stake, they will have borne many of the negative consequences of deprivation, some of which may be irreversible. For example, the results of the ACES study would suggest that even though one can progress out of poverty, childhood stressors like poverty have lasting consequences for the long-term health of the individual. These consequences could only be partly mitigated by receiving a stake upon becoming an adult, but it also means that not every stake-receiver starts off on equal footing. A social insurance model that intervenes to dissolve lines of inequality early on would provide a unique benefit and would be compatible with other policies. In sum, there are numerous innovative and helpful proposals that can supplement the instant proposal in generally increasing resources for children who need and deserve them, but these proposals do not plug the gap created by parental incarceration specifically.

\section{Program Implementation}

The core elements the foregoing program upon which all of the theoretical discussion is based thus far only require that the government provide a nonmeans-tested incarceration insurance payment upfront, that the incarcerated parent be obliged to contribute at least some portion of the cost, and that this contribution displace the accrual of child support obligations for the duration of the parent's prison term. This section explores a number of implementation decisions for structuring an incarceration insurance program designed to benefit children.

Embedded in these recommendations is a critique of existing policies on child welfare. While some recommendations may be too radical to pass political muster everywhere, even if not all of these program details are adopted, a basic incarceration insurance scheme is better than none at all. If we recognize that the state does indeed have obligations to provide for children of incarcerated parents, we must also recognize that there are full and partial ways of fulfilling the obligation. Because no such program has ever existed before, I caution that many design details outlined below are postulates and considerations for optimal policy, not proscriptions. In some, I note that the "right" answer is more elusive, and provide only hypotheses for what a successful program might look like.

Practically speaking, it is unlikely that incarceration insurance would be implemented on a national level. This means that any enactment that occurs on the local and state levels in the form of pilot programs should pay attention to

323. See Bruce ACKerman \& Anne Alstott, The Stakeholder Society (1999). 
these programmatic design options and to structure their programs to inform best practices and effective alternative implementation options.

\section{Initiation}

The insurance could be initiated by a number of parties, including the other parent, family members, social workers, or the state itself. As long as the child has a legal parent who is incarcerated, the program kicks in. This initiation method should be easier than child support order establishment, because the obligation is incurred universally rather than at the election of the custodial parent.

States can choose to allow the child and his non-incarcerated guardian to opt out of the insurance system, but this decision should happen with counseling and full information. While it is possible to imagine why individual families may find this program unpalatable, it is important that adults' preferences about burdening each other and the state do not create detrimental results for children.

\section{Medium of Payment}

The child and her caretaker should receive the proceeds of the insurance in the form of cash rather than in-kind payments or vouchers. Cash's critical advantage in an effective insurance program lies in its fungibility and that its effects can be felt immediately. Because incarcerated parents may have occupied any number of contributory roles prior to incarceration, it is difficult to provide any uniform in-kind payment scheme that would plug the loss in contribution effectively for children. For example, a nonresident noncustodial father could have contributed to the child's welfare primarily through providing childcare while the resident custodial mother worked. For this child, an in-kind payment that would plug the loss that results from that father getting incarcerated would be childcare. However, another child may have received mostly supplemental contributions from her father in the form of baby formula and other foodstuffs. For this child, the relevant plug payment would be food stamps. Without knowing the individual circumstance of each parent's contribution prior to incarceration, it is hard to know the form in which the loss of the parent confers disadvantage on the child.

Furthermore, children's developmental needs change over time, and any in-kind payment that could be critical at time $\mathrm{X}$ may become unimportant relative to other needs at time $\mathrm{Y}$. While cash supports do not plug the loss created by departure of a caretaker, it makes the most sense as the next best alternative because of its fungibility and its ability to provide relief immediately upon receipt and in almost all contexts. 


\section{Amount of Support}

There are several models for determining how much the program should pay to children. One policy permutation is to provide the same amount for all children, and others would adjust the amount based on a number of factors. The latter has options that are more progressive (i.e. based on existing family income) and others that are more regressive (i.e. based on how much support the parent gave before).

A static payment is the approach taken by Garfinkel in establishing the CSAS program, which proposed a $\$ 2,000$ to $\$ 2,500$ universal, non-incometested government guarantee (in 1992 dollars) that "represents less than the cost of raising a child, so it still leaves an incentive for the recipient parent to work, but, when combined with earnings and other benefits, it could substantially reduce poverty and insecurity at practically no cost to the public." ${ }^{324}$ A similar methodology could be used to come up with a figure for the instant proposal: for example, using average child support orders as a guideline, or the average amount provided for child recipients of Social Security survivor benefits, which was $\$ 625$ per month at the end of 2004 . $^{325}$

Alternatively, the program could use a variable payment scheme. One way is to ride on the coattails of the child support enforcement program to determine amounts. However, because at least some portion of children whose parents get incarcerated already have established orders, the amount to be paid already has a prior basis. For children who do not have child support orders for the incarcerated parent-either because none was established, or because the parents were cohabiting or married prior to incarceration-an alternate mechanism could be established. For example, a family court could come up with a baseline amount. Alternatively, a state agency could use the state court's child support order calculator to determine a fallback figure.

Because child support is based partly on how much the nonresident parent is able to make, it is regressive as a policy: children with nonresident parents who are richer get more money than children with poor parents (and when the nonresident parent is poor, the resident parent is likely to be poor as well). In addition, payment received from child support count against TANF benefits, which is also regressive. ${ }^{326}$ One program option is for incarceration insurance

324. GARFINKEL, supra note 24 , at 47 . He calculates that the next two additional children would require $\$ 1,000$ more each, and subsequent children would require $\$ 500$ each. $l d$.

325. Kathleen Romig \& Scott Szymendera, Cong. Res. Serv., RS22294, Social Security SURVIVORS BENEFITS 3 (Oct. 6, 2005), available at http://www.policyarchive.org/handle/10207/ bitstreams/4244.pdf.

326. Child support payments count against TANF cash benefits, unless the state opts to pass through the child support benefit and disregard the amount in calculating TANF benefits. Not all states choose to do so, and many states only do so up to $\$ 50$. Thus, for many poor families, child support orders do not help much with bolstering income. For a survey of state pass-through and disregard policies, see Nat'l Conf. Of State Legis., State Policies Regarding Pass-Through and 
to pass payments to the child. This is controversial because there is a strong state interest in recouping costs. However, providing actual tangible benefits to children regardless of the actions of their parents is a motivator behind the proposal, so it behooves policymakers to seriously consider detaching payments to children from their parents' TANF status.

Finally, there are options to time-limit and/or dollar-limit the insurance, both in terms of how much children receive and in terms of how much the state asks parents to pay back. In theory, children should receive these benefits for as long as they are children. To the extent that these policy choices are infeasible, there may need to be adjustments to ensure some support as opposed to none at all.

\section{Accruing Obligations Against the Parent}

The most direct scheme would be to put the incarcerated parent on the hook for the full amount paid to the child while the parent is in prison. There are a few alternative methods of setting up the parental obligation component. One is to cap the amount owed. Another is to obligate the parent to pay only a percentage, with the exact amount set at the would-be insurance premium for a theoretical open market for incarceration insurance.

The state may want to consider these alternatives in light of the many difficulties in the current child support payback scheme for incarcerated parents. In the status quo, incarcerated parents often accrue far too much child support arrears while in prison, and given the host of employment and earnings barriers post-release, ${ }^{327}$ are unable to pay them back. As a result, arrears build up, further crippling these parents' abilities to become reintegrated into their family lives and parental roles. ${ }^{328}$ These policies do not only exacerbate the disadvantage felt by formerly incarcerated parents, but also harm children by preventing their parents from reintegrating and becoming able to contribute meaningfully and continuously to the children's well-being. There is a real concern that once they get out of prison, felons may be incentivized not to find a job or find a job in the underground market to avoid wage garnishment. As the reality of arrears debt sinks in, they may be even less inclined to take on employment. ${ }^{329}$ This might be mitigated through careful programming.

DisRegard of CURRENT MONTH'S CHILd SuPPORT COLleCted FOR FAMILIES RECEIVING TANFFUNDED CASH ASSISTANCE (Feb. 2012), available at http:/www.ncsl.org/issues-research/humanservices/state-policy-pass-through-disregard-child support.aspx.

327. See supra Part II.B.2.

328. Child support arrears total $\$ 110$ billion nationally. OFFICE OF CHILD SUPPORT ENFORCEMENT, U.S. Dep'T OF HEAlth \& Hum. Servs., Fy 2011 Preliminary Report (2012), available at http://www.acf.hhs.gov/programs/css/resource/fy2011-preliminary-report.

329. See Marcia Cancian, Carolyn Heinrich \& Yiyoon Chung, Does Debt Discourage Employment and Payment of Child Support?: Evidence from a Natural Experiment (University of Wisconsin Institute 
One option is to delay the onset of the debt. Even if the total amount accrued against the parent remains the same, the state should consider a deferred payment system whereby the parent need not begin paying until six months after employment. This way, the immediate marginal withholdings rate on these individuals would not be astronomically high, and would counter the current disincentives for lawful employment.

Another option is to implement programs to keep parents in the gambit of contributing when they can rather than dropping out entirely. In the child support context, there have been innovations in some localities to encourage low-income parents to meet their child support obligations through incentive programs. For example, Baltimore's child support organizations implemented a "Help Us Help You" program, which had incentive arrangements for delinquent payers to make one-time good-faith payments of $\$ 20-25$, after which they would be re-issued the driver's license that had been previously confiscated due to nonpayment, and receive intensive employment placement and retention programs. ${ }^{330}$

Another important policy maneuver that states should seriously consider is to find ways to avoid penalizing previously incarcerated parents who cannot work because they must take care of their children instead. One obvious solution is to credit caretaking against the accrued parental payment amount (whether the care is for the child insured against during incarceration or a new child). Another option is to provide a "leave" model for caretaking such that if the parent does take time off from a paid position for family care (or for disability), the accrued amount would be frozen and no additional penalties would be levied. These policies are desirable, out of fairness considerations for parents with childcare responsibilities, equality-based concerns about gender roles, and concern for child well-being, since putting a heavy burden on parents to work at the expense of caring for their children post-incarceration could be actually detrimental to child well-being.

Finally, as a general matter, the enforcement regime for collecting backpayment for incarceration insurance should not be draconian. A system tailored to the efforts and circumstances of the formerly incarcerated parent will be more beneficial in the long run for their ability to continue contributing to his child's welfare. Thus, best practices in the child support context for arrears forgiveness and reasonable evaluations of inability to pay should be a part of this program as well.

\footnotetext{
for Research on Poverty Discussion Paper no. 1366-09, July 2009), at 20-26, available at http:/www.ssc.wisc.edu/irpweb/publications/dps/pdfs/dp136609.pdf.

330. The success of these programs is hard to measure, as many individuals failed to follow through with the entire program. See Federal Office of Child Support Enforcement Section 1115 Demonstration Grant, Excellence through Evaluation: Final Report (2012) (on file with author) [hereinafter Excellence through Evaluation].
} 


\section{Increasing Opportunities for Contributing}

The state has not made great strides in increasing employment opportunities for former inmates, and should improve in this area. Specifically, the state should continue to bolster investment in education and training opportunities for formerly incarcerated men, and should consider removing civil regulatory barriers to certain employment sectors, public benefits, and housing wherever it is safe to do so.

A final, more radical consideration may be to allow currently-incarcerated parents to work in prison for "wages," which would reduce the amount of incarceration insurance payment owed, or bolster the payment to their children. In the status quo, prison labor is a vast apparatus that pays inmates a minimal amount in commissary accounts. Some scholars and practitioners advocate eliminating prison labor or increasing the amount prisoners get paid in their cash commissary accounts. Alternatively, perhaps inmates could opt to get paid in deductions in the total amount owed for their children's incarceration insurance, or to increase the total amount of incarceration insurance paid to their children, in lieu of being paid in their commissaries. The rate of deduction should be higher than that of the low-wage commissary payments, in order to incentivize opting into this program.

This plan would have several benefits. First, it would allow inmates to reduce the future burden of arrears post-release. Second, it would allow inmates to contribute if they think their children and children's caregivers need more resources than provided by the insurance. Third, it would create a constant linkage option for inmates to their children. The inmate parent would be able to make autonomous decisions about whether and how to provide for their children while in prison, possibly counteracting some of the alienation and detachment effects on parenting identity.

Another potential program is for the released inmate to opt into a transitional "work probation" period, whereby the ex-felon is still restricted in many ways: he would work in jobs mandated by the government, until he pays off the entirety of or a large percentage of the accrued amount. This would create the added benefit of developing work skills for eventual reintegration, but would also create additional opportunities for paying back.

\section{Transparency}

If state, regional, or federal governments implement this proposal, one interesting policy maneuver to promote awareness and to manage costs is to publicize the amount of money being spent on this program as a percentage of the total prison budget. This serves two purposes. First and most importantly, by publicizing the cost, the state is recognizing-and making the public recognize-that there are indeed collateral costs of mass incarceration. 
Publishing the cost of this program as a percentage of the prison budget reminds the public that this program is linked to the regime of incarceration rather than the regime of entitlement programs. This is an important distinction because it forces the recognition that incarceration policy is a choice and that the choice creates collateral consequences. Especially given that these collateral consequences have been hidden in the past, transparency promotes awareness. Second, publicizing the cost is also a good checking mechanism, and may allow the program to gain support from budget conservatives who are worried about cost ballooning.

\section{Limitations and Caveats}

This proposal does not create a perfect solution. Nevertheless, it addresses a major risk in the lives of many children-many of whom are already especially vulnerable. Its implementation will almost certainly create dilemmas for the implementer. I examine some grounds for hesitation below, accepting some as obvious but nonfatal flaws and countering others as minor or misconceived. This is by no means a comprehensive list, and some of the potential counterarguments are already anticipated in subparts above, but in sum, I aim to address the most pressing contentions.

\section{Many Ex-Inmate Parents Cannot or Will Not Pay}

This argument expresses the concern that because many ex-felons cannot find adequate employment, and because some will repudiate the obligation to pay, there is a good chance that some ex-inmate parents will not pay the full amount owed to the government for the subsidy to their children. This may be especially true if they have accrued a large amount by virtue of long sentences or if they have multiple children.

But insofar as the government has an obligation to provide for these children when parental incarceration occurs, the state has an obligation to pay the price of upholding that obligation, regardless of whether a particular parent can pay the state back. Thus, the fact that the full amount may not be recouped is not fatal to the internal logic of the proposal. ${ }^{331}$ Indeed, 1 propose this plan with the full understanding that the government would likely not recoup the full costs from the parent after incarceration.

In fact, that non-payment risk exists is a structural component of the proposal itself. This creates an incentive for the state to provide better reentry

331. The fact that the full amount may not be recouped would mean that some of the benefits outlined in Part IV.B.2-about the potential of the incarceration insurance program to counter parental alienation-would be slightly diminished, only to the extent that some portion of parents realize while in prison that they cannot pay their share. 
policies for ex-felons. This may seem counterintuitive, but the proposal reframes mass incarceration as a state policy: if the state has something direct to gain from making sure ex-felons find employment, it may be better incentivized to improve opportunities for transitional jobs, housing, drug treatment, and other comprehensive reintegration provisions. ${ }^{332}$ Alternatively, if it has something to gain from reducing the number of children to whom it must pay incarceration insurance, the state has an incentive to reduce the number of parents going to prison in the first place.

For the parent committed to prison for life or for long periods of time, there is no feasible way to pay back the government. Above, I discussed the possibility designing a prison-work system where the parent could work to pay into the insurance scheme. However, the effectiveness of this proposal is still limited. These are fringe cases that the proposal will not be able to address. Similarly, as a growing number of federal crimes are for immigration offenses where parent inmates are deported upon completion of their sentences, it is not clear how the state could enforce their contributions. For all of these concerns, the bottom line is that though the parent may be unable to complete his end of the obligation, that does not free the state to ignore its obligation, which it can and should fulfill.

Therefore, though theoretically the proposal works best when the government provides the upfront outlay and the parent eventually pays back, the success of the program as a policy tool does not rely on repayment. Rather, the proposal reframes the repayment issue as a dynamic one and leaves it to the government to decide where to focus its energies in terms of recuperating costs.

\section{Incentives To Go To Prison?}

Another counterargument is that by providing for their children, incarceration insurance actually confers a benefit on felons. This is a very important concern. First, as a normative and common-sense matter, decreasing the deterrence effect of prison is bad for law enforcement. Second, it is inequitable to create a policy that confers a benefit for lawbreakers in comparison to those who did not break the law.

However, this policy is unlikely to give people an incentive to go to prison. First, under this proposal, once the incarcerated parent leaves prison, they eventually have to pay the government back. Second, as the analysis in Part II.B explained, a criminal record reduces earnings potential dramatically, and individuals cannot stand to gain in the long term from going to prison even with this marginal benefit to their children in the short run. 


\section{Noneconomic Harms}

Incarceration insurance is not designed to directly alleviate noneconomic harms visited up on children by parental incarceration. Although financial support might assuage some of the negative consequences that come as a result of second-order effects of economic hardship caused by parental incarceration, it will not necessarily have much of an impact on the emotional and developmental harms caused by the traumatic event of parental exit through incarceration. Other policies aimed at more humane arrest procedures, improving placement and visitation, and providing inmates with meaningful opportunities to interact with their children remotely could help. But ultimately, tragically, there may be nothing that can truly soften the blow of seeing a parent committed to prison. There may be nothing that can really heal the child's heartbreak from prolonged periods apart from his parent. But incarceration insurance is unlikely to aggravate these fundamental problems of forced familial separation; instead, it can help ease the holistic burden on families and children by providing support where it can.

\section{Under-inclusiveness}

Others may question why children whose parents get incarcerated should receive extra funds while children of ordinarily neglectful parents do not. But parental incarceration is unique both because, save death or severe disability, it is the most totalizing incapacitation of a parent's ability to provide resources to his children, and because this incapacitation is imposed by the state.

Evidence suggests the harm of incarceration on children may be greater than mere absence of support. ${ }^{333}$ Thus, on a comparative level, children of incarcerated parents on average may still be worse off than similarly situated peers, even if they do receive this insurance. Indeed, when parents leave their children through other exits, the state expects the exiting parents to continue to fulfill parental duties. Of course, the government does not always do a particularly good job of enforcing that expectation, and preferences certain forms of exit over others. ${ }^{334}$ But the instant proposal addresses the circumstance when the parental duty literally cannot be fulfilled because the government imposes the barrier.

333. See supra Part II.A.

334. For example, the state makes implied and explicit distinctions between the death of a working parent (Social Security) and having a nonresident parent. See Dorothy Roberts, The Absent Black Father, in LOST FATHERS 45, 53 (Cynthia Daniels ed., 1998) (arguing that the state makes a distinction "between children whose mothers become widowed and children whose mothers never marry or get divorced. The former are not stigmatized at all and receive survivors' benefits through Social Securitythe most generous type of public assistance paid to mothers. The latter are more likely to receive [welfare] ... benefits, which are both disparaged and meager."). 
In the end, there may be cases where the children of incarcerated parents under this system are better provided for than the children of deadbeat noncustodial parents under this scheme. In practice, under-inclusiveness is a harm we may have to accept. Though good policy designs should try to minimize it, the problem posed is not inherent to the status of the recipients of incarceration insurance. Instead, if the state also ramped up child support enforcement and employment opportunities in general, it would alleviate the comparative disparity. Indeed, virtually all child welfare programs suffer from the same problem. For example, survivor benefits are under-inclusive and create a comparative advantage for children with dead parents, but that is not considered a good reason for denying them those benefits.

\section{E. Buying In}

The proposal for incarceration insurance is novel, but it is not wholly liberal or conservative. Novelty also has drawbacks. Implementing a program such as this one requires attention to how stakeholders might react. There are two parallel concerns about "buy-in": on one level, it's the policymakers; on another, it's the families.

\section{Policymakers Buying In}

The proposal is driven entirely from the perspective of the child, and this perspective should be persuasive to points along the political spectrum. All constituencies-at least in theory-should consider persuasive the three theoretical underpinnings described in Part III, but different parts may appeal to some more forcefully. Political liberals will likely agree with the focus on underprivileged families and the government's obligation to correct past wrongs. Though they may prefer a more universal assurance system, this proposal does not foreclose those options. Conservatives may find this proposal attractive because it aligns with the responsible fatherhood movement, ${ }^{335}$ and the potential for the program as an investment to reduce the collective societal costs of parental incarceration and childhood disadvantage. Though they may have budget concerns, the proposal focuses on both on bolstering child welfare and keeping parents accountable. Libertarians may find persuasive the arguments about negative externalities and shoring up parental responsibility, and perhaps see the program as a way for the state to recalibrate its own interference in social control.

Ultimately, the path towards implementation will likely involve trade-offs. The previous subsections delineate some of those options, and ultimately, these

335. See generally anNa Gavanas, FatherhOOD POlitics IN THE UNITED States: MASCULINITY, SEXUALITY, RACE, AND MARRIAGE (2004). 
options will adjust to the political realities. For example, the question of just how much the state should ask from the parent in the post-release payback system and whether the payments will count against TANF benefits will depend on what various policymakers are comfortable with. They must balance the commitment to alleviating bad outcomes for families with the commitment to responsible parenthood and budgetary realities.

Some scholars believe that social insurance is viewed by the American public as more acceptable than "entitlement" programs. ${ }^{336}$ However, more nuanced analyses of support for public programs suggests the divide is not as simple as universal versus categorical. Martin Gilen's research on support for universal and means-tested programs demonstrates that both the poor and nonpoor public generally have consistently higher levels of support for nonwelfare programs, whether universal or categorical. Support for welfare is lower generally, and declines as income goes up. ${ }^{337}$ Robert Greenstein points out that some means-tested programs in a relatively benefits-hostile periodthe Reagan Administration-actually were preserved or expanded while universal programs were cut. ${ }^{338}$

Regardless of historical public opinion tendencies, categorical eligibility for specific programs does often spark suspicion about deservingness, whereas programs that insure against unknown risks are less likely to invite such suspicion. However, incarceration insurance does not share some of social insurance's politically palatable traits. Because "social insurance programs engage most of the electorate precisely because they cover common risks and insure most of the population ... [a]nd because practically everyone is both a contributor and a potential beneficiary, the politics of social insurance tends to be of the 'us-us' rather than 'us-them' form." ${ }^{339}$ However, even though in reality the advent of parental incarceration is something that can happen to any child, the American public is not likely to start thinking of themselves as in the same group as families with incarcerated parents. Indeed, opposition to broad social insurance schemes for children hews along the line of the argument that children are blameless and deserving, but they are tied to parents who may not be. ${ }^{340}$ For children, "the risk to be insured against is the risk of being born into and raised in a poor household . . Because the family is an economic unit, society cannot lift the poor child from poverty without making the family non-

336. See Theda Skocpol, Targeting within Universalism, in THE URBAN UNDERCLASS 432-33 (Christopher Jencks \& Paul E. Peterson eds. 1991) (arguing that universal programs receive more support as the public believes they have a "direct stake" in these programs).

337. Martin Gilens, Why AMERICANS Hate Welfare 54 (1999).

338. Robert Greenstein, Universal and Targeted Approaches to Relieving Poverty: An Alternative View, in THE URBAN UNDERCLASS, supra note 336, at 437.

339. MARMOR, MASHAW \& PAKUTKA, supra note 22, at 219.

340. Linda Gordon, Who Deserves Help? Who Must Provide? 577 AnNAlS AM. ACAD. POL. \& SOC. SCI. 12, 22 (2001). 
poor." 341 There is a fear that parents will free-ride on the moral deserts of their children. $^{342}$

Thus, it is extremely important that in designing a policy for incarceration insurance, policymakers emphasize the perspective of the child as the unit of analysis and the direct beneficiary. Social insurance for children may avoid the problem of deservingness suspicion if decision makers focus on the fact that "children's actions are not implicated in their poverty." ${ }^{343}$ An important policy factor is to ensure that the program does not act to disincentivize work. ${ }^{344}$ This program in particular can accomplish that precisely because parents are obligated to pay back. Thus, though the proposal is not nearly as "ambitious" in its reach as some of the broader proposals for social insurance for children, its targeted nature is actually advantageous from a theoretical and a political perspective.

By concentrating on a specific trigger for childhood disadvantage, incarceration insurance is more limited in scope and expense than a more universal program; this may make it more politically viable. Gillian Lester argues that voters and decision makers use a trio of factors to decide if they support redistribution: reciprocity, empathy/groupism, altruism, and beliefs about deservingness. ${ }^{345}$ The general reforms targeted at mass incarceration, while probably astute and just, are prime candidates for failing the above factors because the primary beneficiaries of the policy are felons or potential felons. Voters do not think of decriminalization efforts as public goods that create reciprocal benefits, nor do they think of themselves as falling within the same "group" as felons and potential felons, nor do they believe that these folks deserve any benefits. At first glance, the proposal for incarceration insurance may seem at risk to trigger many of the same "otherness" problems. It does not appear that the general public is "in this together" as Lester puts it-after all, most people are not children of felons. However, because the proposal focuses on "deserving" recipients, it may (justifiably) pass muster. Lester points out that "in dictator games, proposers give about three times as much when they are told the recipient is the American Red Cross than when the subject is anonymous," noting that various studies show "people express stronger support for redistribution if they believe the recipient's need is caused by circumstances

341. GRAETZ \& MASHAW, supra note 23, at 119.

342. This fear is overstated for several reasons, most obviously because it starts with a baseline assumption that parents ought not receive assistance from the state in caring for their children. See FINEMAN, supra note 210 , at $42-49$. Further, the stark gender disparities in parental care-and the resulting relative poverty of single mothers-demonstrate that the "free rider" fear is not nuanced enough.

343. GRAETZ \& MASHAW, supra note 23, at 120.

344. FINEMAN, supra note 210 , at $42-49$.

345. Gillian Lester, Can Joe the Plumber Support Redistribution? Law, Social Preferences, and Sustainable Policy Design, 64 TAX L. REV. 313, 340-50 (2011). 
beyond his or her control."346 That children cannot control whether their parents go to prison is both normatively important and could be critical for coalescing support. If appropriately framed, policies directed solely at child welfare might be more likely to succeed than other entitlement and redistribution policies. ${ }^{347}$ The moral imagination of the political process may be lacking in many respects, but it might be more robust when considering the welfare and just deserts of underprivileged children.

\section{Families Buying In}

Second, and as importantly, is buy-in on the proposal from the perspective of inmates and their families. This program makes major demands of these parties: it requires that an already-disadvantaged individual pay back the government at a vulnerable transition point in his life. It is situated within a regime that has-not unreasonably - bred a high level of mistrust among poor communities. "In high-incarceration neighborhoods, many residents do not believe that the state's justice agencies work on their behalf." "348 A recent study found that "neighborhoods with relatively large concentrations of former prisoners" had more negative attitudes about the role of authority and legitimacy of the law. ${ }^{349}$ Because incarceration insurance rests against a backdrop of existing suspicion, it is likely to face legitimacy problems.

Poor families have reason to be skeptical and apprehensive. Inmates may feel overburdened, or that they are being treated as "mere paychecks." 350 However, on the whole, these demands are far less demanding than the status quo, where child support arrears accrue against the incarcerated parent without a cent going to their children. Nevertheless, practitioners should pay careful attention to explaining the underlying rationale for the incarceration insurance program. First, they should spell out upfront specifically what is required of the incarcerated parent and how he may achieve those requirements. Thus, these efforts may parallel similar ones in the child support context, where there is a dual effort for "requiring poor noncustodial fathers to be more reliable child support providers" and for "enabling such fathers to meet their responsibilities permanently, e.g. avoiding arrears." 351 This enterprise, called "managing the risk," involved efforts to "help [noncustodial parents] find[] good jobs, . . . enroll[] in peer-based fatherhood programs and . . . be[] more effective at

346. Id. at 347 .

347. Lester uses empirical research to explain the factor of deservingness in the abstract, but it is difficult to know how this plays out in real life. $I d$.

348. ClEAR, supra note 8 , at 112 .

349. See id. at 113 (citing Robert D. Crutchfield, Neighborhoods, Collective Efficacy, and Inmate Release: A summary of Preliminary Analyses. Unpublished paper (2005)). See generally Tom R. Tyler, Psychological Perspectives on Legitimacy and Legitimation, 57 ANN. REV. PSYCHOL. 375 (2006).

350. See EDIN \& NELSON, supra note 83, at 118.

351. Excellence through Evaluation, supra note 330, at 7. 
staying on top of child support obligations and tell[ing] child support systems when their cases needed modification." 352

Second, packaging the program with a bundle of other ways of connecting the inmate with the child, such as visitation programs, parenting classes, and other reforms, would help situate incarceration insurance as one of a set of policies directed at preserving parenthood bonds, as opposed to one that milks the inmate of resources once he gets out. These efforts are necessary not just for the sake of abstract legitimacy, but also for sustaining and encouraging long-term parental contributions to their children's well-being.

\section{CONCLUSION}

That so many children suffer incarceration risk in America is a catastrophe of massive proportions. This is not to say that any individual parent did not deserve to go to prison, or that incarceration is the only factor driving economic instability for their children. However, the major effect of mass incarceration is the exacerbation of childhood disadvantage through deprivation of resources in parental incapacitation. The status quo writes off incarcerated parents. In doing so, it also writes off their children.

In our society, parents are responsible for supporting their children, through physical care, financial assistance, and emotional support. Many fail their responsibilities for a number of reasons, but one of the biggest structural impetuses driving out parents is the American prison, a "system of social control unparalleled in world history," removing millions of parents and barring them from supporting their children. ${ }^{353}$ As a result, children bear the cost of society's expressed interest-justified or not - in mass incarceration.

Incarceration insurance, like virtually all other reactive proposals, will not solve the mass incarceration problem. ${ }^{354}$ It is a move to address some of its particularly pernicious consequences. It alone cannot solve for many of the other deep problems, such as racism in policing, felon disenfranchisement, and the failure to reintegrate former felons into society. It thus should not distract from the agenda to reverse the pervasive social injustice disaster that is the American penal system. Large-scale recognition of mass incarceration as a man-made social disaster is underway, and this proposal helps raise awareness of one type of consequence arising from it. However, it is by no means an effort to displace other reform projects targeted at addressing similar consequences, such as quests to get judges to consider parental status at sentencing and to get prisoners allocated to locations closer to their families.

352. Id.

353. ALEXANDER, supra note 28 at 8.

354. See ClEAR, supra note 8 , at 181 (noting that rehabilitation programs, alternatives to incarceration, and reentry programs are good efforts, but will not solve mass incarceration). 
Nor should scholars and policymakers bank on the possibility that the U.S. will successfully walk back mass incarceration policy. ${ }^{355}$ It is possible that "the punitive apparatus of criminal justice, with its guarantee of continuing collateral damage, continues unabated." 356 In the meantime, children continue to suffer the negative externalities of the state's grand social experiment. There is an urgent need for society to make good on its obligation to compensate these children, who neither chose to be born to parents who will go to prison, nor chose the policies that brought so many of their parents there, and for so long, in the first place. However, incarceration insurance could be a powerful tool to drive a wedge between the existing advent of mass incarceration for adults and the subsequent catastrophic consequences for their children.

Intentionally or not, the American criminal system is "eroding the fabric of family life in poor minority communities." 357 Insofar as financial assistance stanches the most direct outflows of harm from incarceration for inmates' children, it is an important policy mechanism for promoting the well-being of this vulnerable population. The proposal for incarceration insurance aims to resolve a dilemma that is currently wholly unaddressed and that confers very real, severe, and negative consequences for children.

The foundation of American democratic governance lies in equality of opportunity; a foundation of our moral imperative is to provide for children in need. At this moment, vast numbers of American children are in need because the criminal justice system has left them behind. American children need and deserve incarceration insurance. Without it, they unjustly suffer silently as the ignored, uncompensated victims of private tragedies and public policy.

355. For discussion on the status of these reforms, see, e.g., CLEAR, supra note 8, at 177; David Cole, Turning the Corner on Mass Incarceration? 9 OHIO ST. J. CRIM. L. 27, 33, 37-39 (2011).

356. CLEAR, supra note 8, at 208.

357. Western \& McLanahan, supra note 64 , at 322. 



\section{- Y A l \\ J O URNAL OF}

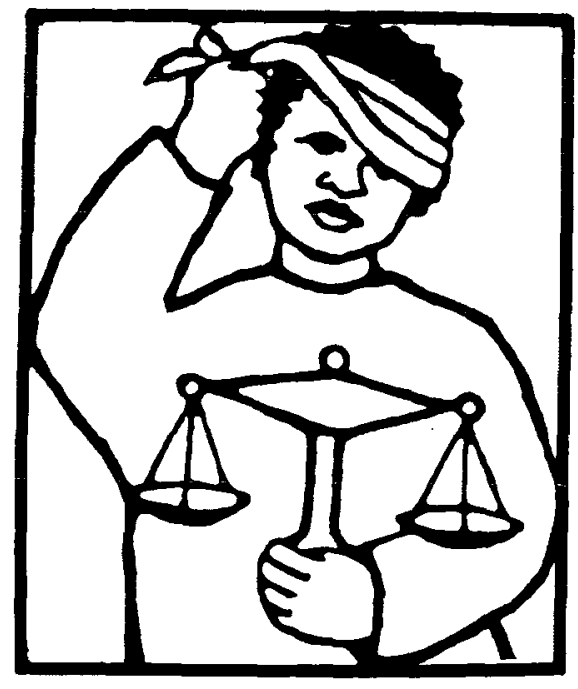

L A W A N D

F E M I N I S M 
The Yale Journal of Law and Feminism is published twice a year, in the Summer and Winter, by a student-run organization at the Yale Law School, 127 Wall Street, New Haven, CT 06511.

Mailing address: P.O. Box 208215, New Haven, CT 06520-8215

Webpage: http://www.law.yale.edu/academics/YJLF.htm

Email: lawandfeminism@yale.edu

Subscriptions: Subscriptions are $\$ 30.00$ per volume for institutions and $\$ 20.00$ per volume for individuals. Subscriptions paid by institutional check will be billed at the institutional rate of $\$ 30.00$. All subscriptions will be renewed automatically, unless the subscriber otherwise notifies the Journal. Back issues can be purchased at the rate of $\$ 16.00$ for institutions and $\$ 10.00$ for individuals. Reprints of individual articles can be purchased for $\$ 5.00$ per page. Claims for non-receipt of issues will only be honored for one calendar year from publication date. Inquiries regarding subscriptions can be made by email or through the mail at the above address.

Manuscripts: The Journal welcomes the submission of unsolicited articles, comments, letters, and fiction for consideration. Manuscripts cannot be returned without a self-addressed, stamped envelope. We prefer electronic submissions in Microsoft Word; otherwise, we recommend that manuscript submissions be accompanied by a disk with the piece in a format readable by a PC using Microsoft Word.

Production: The citations of the Journal follow THE BLUEBOOK: A UNIFORM SySTEM OF CiTATION (Columbia Law Review Ass'n et al. eds., 19th ed. 2010). The Journal is printed by Joe Christensen, Inc., in Lincoln, Nebraska. The Journal is typeset by Journal staff members and printed on recycled paper containing fifteen percent post-consumer waste.

Copyright (C) 2014 by the Yale Journal of Law and Feminism. Publication number ISSN 1043-9366. This issue should be cited as 26 YALE J.L. \& FEMINISM 2 (2014).

Cover illustration by Jacqueline Coy Charlesworth.

Graphic design by Ann Mackey. 


\section{- Yale Journal of • LAW AND FEMINISM \\ VOlUme tWenty SIX - NUMBeR tWo - 2014}

\section{ADVISORY BOARD MEMBERS}

Jacqueline Berrien

Washington, D.C.

Clare Dalton

Boston, Mass.

Lucinda Finley

SUNY Buffalo

Law School

Owen Fiss

Yale Law School

Shelley Geballe

Connecticut Voices for Children

New Haven, Conn.

Elizabeth Holtzman

Herrick, Feinstein LLP

New York, New York

Sherrilyn Ifill

University of Maryland

Law School

Sylvia Law

New York University

School of Law

Catharine MacKinnon

University of Michigan

School of Law
Martha Minow

Harvard Law School

Frances Olsen

University of California

Los Angeles School of Law

Judith Resnik

Yale Law School

Barbara Safriet

Lewis \& Clark Law School

Vicki Schultz

Yale Law School

Reva Siegel

Yale Law School

Kate Stith

Yale Law School

Jamienne Studley

Public Advocates Inc.

San Francisco, CA

Patricia Williams

Columbia University

School of Law 


\section{- Yale Journal of - \\ LAW AND FEMINISM \\ Volume tWenty SIX - Number tWo - 2014}

\section{Editor-in-Chief \\ Kaitlin Welborn}

Managing Editor

Ashley Anderson

Articles Editors

Jade Chong-Smith

Rachel Dempsey

Samantha Godwin

\section{Board Members at Large \\ Michelle Cho \\ Marcus Curtis \\ Jessica Hunter \\ Alex Messiter}

\section{Editors}

Dani Abada

Celina Aldape

Janine Balekdjian

Bianca Bamgbade

Humza Bokhari

Juliana Brint

Liz Dervan

Angela Doyle

Katie Haas

Olivia Horton

Sophie House

April Hu

Arielle Humphries

Ashley Ingram

Scout Katovich

Emma Larson

Liz Leiserson

McKaye Neumeister

Rebecca Ojserkis

Rumela Roy

Shelle Shimizu

Julia Solorzano

Sophia Wang

Liz Willis 